\title{
Fairground Architecture and Crowds
}

DOI:

10.1080/13264826.2019.1656269

\section{Document Version}

Accepted author manuscript

Link to publication record in Manchester Research Explorer

\section{Citation for published version (APA):}

Walker, S. (2019). Fairground Architecture and Crowds. Architectural Theory Review, 23(2), 256-286. https://doi.org/10.1080/13264826.2019.1656269

\section{Published in:}

Architectural Theory Review

\section{Citing this paper}

Please note that where the full-text provided on Manchester Research Explorer is the Author Accepted Manuscript or Proof version this may differ from the final Published version. If citing, it is advised that you check and use the publisher's definitive version.

\section{General rights}

Copyright and moral rights for the publications made accessible in the Research Explorer are retained by the authors and/or other copyright owners and it is a condition of accessing publications that users recognise and abide by the legal requirements associated with these rights.

\section{Takedown policy}

If you believe that this document breaches copyright please refer to the University of Manchester's Takedown Procedures [http://man.ac.uk/04Y6Bo] or contact uml.scholarlycommunications@manchester.ac.uk providing relevant details, so we can investigate your claim.

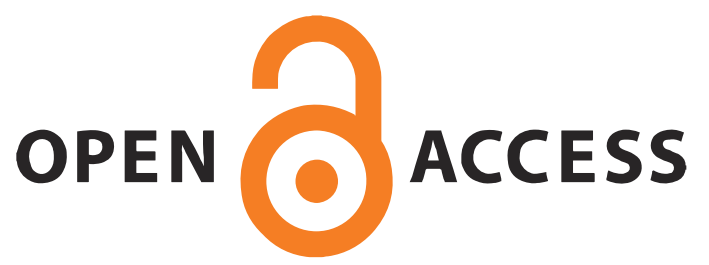




\section{Fairground Architecture and Crowds}

Drawing on fieldwork at travelling fairs in England, this article uses a number of concepts—crowd crystals; involvement contours; cacophony; intercalary elements - to read the heterogeneous interrelationships between fair-going crowd dynamics and fairground architecture. The article notes an apparent lack of interest in both these entities (from crowd theory and architectural theory respectively); establishing an historiographical account of this (lack of) interest, it situates fairground crowds within and against crowd behaviour, and crowd theory, more generally; and draws on assemblage theory to develop an account of the fairgoing crowd, and fairground architecture, that is responsive to its particular characteristics.

Keywords: travelling fairgrounds; assemblage theory; playful crowd; Manuel DeLanda; Erving Goffman

\section{Intro}

"[C]rowds draw themselves. It is easier to draw a crowd of thousands than to show a flicker of doubt passing over one person's face.”-William Kentridge ${ }^{1}$

At the fairground, broadly accepted definitions and understandings of both architecture and crowds fail to find a comfortable fit, they are called into question or put under some pressure. I am slightly exercised by this: much worrying about crowd behaviour (bad behaviour) has been pinned on fair-going crowds, yet the latter do not seem to have provided much grist for the mill of crowd theory. Similarly, architectural theory and practice have broadly dismissed fairground architecture because in its flimsy, gaudy and ephemeral glory it does not display the qualities or characteristics usually drawn upon to define architecture. 
I do not want to dwell at length on the extent to or ways in which fair-going crowds might be different from other crowds that have attracted more attention from theorists, although I will sketch out some of these differences in order to set the scene below. Historian Mark Harrison in his book on crowds in $18^{\text {th }}$ and $19^{\text {th }}$ century English towns, observed how "[t]he susceptibility of a crowd to description as a single, describable, individual is one of the means by which those who commentate upon crowds attempt to make sense of them. ${ }^{, 2}$ In this article, I follow a different approach, taking up something of Kentridge's challenge: avoiding the easier treatment of the "crowd of thousands," my concern is to counter the tendency towards reduction in ways that acknowledge the heterogeneity of the fair-going crowd while also attempting to make sense of it. ${ }^{3}$ Without suggesting that other crowds are homogeneous, they have generally been drawn around a particular focus or spectacle (an execution, a political leader, a religious or regal parade, or a sports event, for example). A broad distinction can be made between these and the fair-going crowd, which is drawn to and moves between multiple attractions, and within which the roles of constituent individuals shift between bystander, spectator and participant.

These particular characteristics draw attention to the influence, agency even, of the various rides and attractions that establish the fairground. In contrast to other crowds, which tend to take place within or against the backdrop of existing architectural or urban settings, I argue that fairground architecture plays a significantly different role, not only within the dynamic of the fair-going crowd, but also in the way it operates to re-purpose and bound particular sites. By fairground architecture, I designate not only the tangible objects (the rides and attractions) that are brought to the fair, but also the various legislative and informal rules that govern its organization, and the atmosphere 
and affects that such an arrangement of rides produces when occupied by a crowd. The main contribution of the article is to analyse crowds and this complex materiality of the fairground situation together. Operating at the intersection of crowd theory and architectural theory, this novel approach establishes a discussion that takes heterogeneity not simply in terms of allowing various different perspectives in an epistemological, but in a more thoroughgoing ontological, sense: moreover, by thinking these two debates together, it also gives back to both separately.

The particular fairs that I am considering are travelling fairs that bring together rides, attractions, and food stalls, and which are set up for a short time - typically two or three days - in towns and villages all over the UK. The recorded histories of many fairs date back nearly 800 years, but they are almost certainly much older, and remain hugely popular forms of entertainment. They take on various forms, squeezing into impossibly tight urban and peri-urban spaces, while others fill market places or take over open fields. For reasons of space, I will restrict the focus of my analysis to crowd interaction with a loose cluster of rides known in the trade as the 'core-four,' and I will restrict my reference to three specific examples of fairs drawn from extensive fieldwork (part of a larger, ongoing longitudinal study) undertaken in the UK between 2010 and the present: Ilkeston and Hull Charter Fairs, and the Newcastle Hoppings. Fieldwork involved direct observations of crowd behavior and dynamics; durational and time-lapse photographic surveys; interviews with showmen, enthusiasts and officials; and detailed measured studies of rides. This was supplemented by archival work in the collections of the National Fairground and Circus Archive, particularly their historical photographic collections, document analysis of the World's Fair, and their official and grey legislative literature collection. 
Characteristics of the rides comprising the 'core-four' — the Dodgems, Waltzer, Twist and Miami - are set out in figure 1. The Dodgems (first introduced in 1928) is a covered ride, usually open to the sides. It comprises around twenty small cars (usually two seater) that can drive around the ride's congested main space. Uniquely for fairground rides, punters have control over the speed and course of their car. Whether they choose to 'dodge' other cars is up to the drivers. The Waltzer (1933) is also enclosed, where tub-shaped cars carrying up to four or five punters are free to spin independently on a larger rotating and undulating platform. In practice ride attendants usually spin cars. The Twist (1960) is open to the elements, and configured with cruciform clusters of seating that rotate in the opposite direction to a tricorn main frame. All rotation is in the horizontal plane. The most recent ride is the Miami (introduced in 1990), comprising a linear arrangement of seating (typically 18 -in- a-row) that moves in a vertical plane following a circular pattern. Like the Twist, it is open, and the ride controller determines the speed of motion. All these rides are decorated with unique artwork, and they will play distinctive music and sound effects, accompanied by light shows and dry ice.

The term core-four is an extension to the better-known 'holy trinity' (Dodgem, Waltzer and Twist). ${ }^{4}$ These groupings designate what are perceived to be the essential ingredients of the contemporary fairground, although they will be supplemented by a wide variety of other rides (and 'juvenile' versions of these rides) as well as stalls selling food and drink, other attractions and games of skill and chance. I would argue that there is now a need to extend this designation further in order to include popular 'big ticket' rides such as Oblivion or Mach-2 (and perhaps pushing the collective term 
to 'fundamental-five'). These recently-developed thrill rides are highly engineered, significantly larger and faster than the core-four, (Mach-2 subjects punters to forces of 3.5G, for example) and often have far more complex trajectories of motion. I will introduce one example towards the end of the article — a ride called Air — in order to extend the main focus on crowd behaviour around and on the established core-four through comparative analysis with these newer additions.

The three fairs I will refer to are amongst the largest annual fairs that take place in the UK. Their histories, siting and arrangements differ: Ilkeston Fair has remained on the same town-center site since it was Chartered in 1252; Hull Fair was established by charter in 1278 , but in 1888 was relocated (rather than being abolished completely) from the city center to a site on the periphery as a compromise that removed the crowds - and associated behaviours - from the polite civic activities the Victorians deemed more appropriate for that central location. ${ }^{5}$ As a corollary to this banishment, the Hoppings emerged as a counter-fair, a 'temperance festival', in 1882 and remains roughly on its same site on the common land of Newcastle Town Moor, located on the periphery of the city center. These three differing histories are reflected in their differing architectural characteristics.

As indicated in the layout plans shown in figure 2, the rides and attractions at Ilkeston have to be located within the existing fabric of the town, while Hull Fair and the Hoppings face no such constraints, and are organized in long avenues. The latter give the impression that the fair's attractions, and crowds, simply continue out into the distance, extending further than the eye can see (the longest avenue at the Hoppings is over $700 \mathrm{~m}$ in length). Rides and attractions arranged along the edge of these fairs 
provide a clear boundary that encloses the fairground environment and helps to contain and amplify the atmosphere that it generates. These two different boundary architectures both operate to produce what appears to be a "closed" crowd in what is actually an "open" situation. ${ }^{6}$ In addition to these visual and material aspects of the fairground experience, the importance of invisible (though not immaterial) elements should not be underestimated: the characteristic smells of diesel, fried food, candy-floss and doughnuts, as well as the sounds and noises of the fair (loud music, screams and laughter — and occasional crying — generators, amplified and ambient noises). As cultural historian Ian Trowell emphasizes, the fairground offers "a deliberately noisy and complex soundscape... [a] noise [that] is legitimized and celebrated as part of the fairground experience."7

Analysis proceeds using a number of focused concepts to examine crowd-architecture interaction. These concepts - crowd crystals, involvement contours; cacophony; intercalary elements - are borrowed from various works on crowds or other gatherings, and will be introduced within the main text. The broader approach is informed by Assemblage theory, in particular the work of philosopher Manuel DeLanda, and the framework (or 'meshwork') that this provides for a consideration of the multiple, heterogeneous ingredients and exchanges that are witnessed on the fairground. The empirical data considered here does, in turn, put aspects of DeLanda's work under pressure, an issue to which I will return in the conclusion.

\section{Crowds, crowds, crowds}

Although here is not the place to rehearse crowd theory more generally, it does make sense to introduce certain tendencies that contextualize the following descriptions and 
treatment of fair-going crowds. The first of these is an enduring tendency to refer to natural phenomena as metaphors for crowd behaviour, irrespective of the political or disciplinary position of the writer. In particular, watery metaphors abound (waves and tides, rain, floods, rivers, seas, oceans, and swamps), as well as heaps, fire, avalanches, electricity, or particles. ${ }^{8}$ This is an issue to which I will return below.

Despite varying motivations, the intention of these metaphors was to emphasise the qualitatively different constitution of the crowd and the individuals that comprised it. As literary theorist David Roberts expresses this in an essay surveying modernist writing on crowds: "The crowd can be anybody and everybody, since the decisive characteristic of crowds is their fusion of individuals into a common mind or emotion that dissolves personal and class distinctions. As a member of the crowd the individual feels, thinks and behaves differently". ${ }^{9}$ Combining these two tendencies, the writer Elias Canetti claims that 'we' are able to see the modern crowd "in its nakedness, in what one might call its biological state". ${ }^{10}$

Not only do crowds become at once de-humanised and naturalized in these ways, they were also increasingly invested with pejorative characteristics. Mark Harrison notes the general presumption of crowds as "inherently violent and disruptive". ${ }^{11}$ In his wideranging 'treatise' The Age of the Crowd, social psychologist Serge Moscovici recounts notions of the crowd as irrational, unthinking, savage or child-like, malleable, suggestible (inclined to somnambulism, hypnotism, dream and so on), while feminist writer Elizabeth Wilson has observed how the modern crowd was increasingly invested with purportedly female characteristics such as hysteria, as well as being linked to 
criminals and other minorities, liable to rush to extremes of emotion, a composite threat to the individual male patriarchs of the city. ${ }^{12}$

These attempts to characterize crowds quickly became caricatures (a fate also suffered by the categorization systems put forward by many crowd theorists). Notwithstanding these qualifications, the fair-going crowd does not fit neatly into any of the various categories/types offered. Moreover, the fair-going crowd doesn't figure in the theories of any of the main protagonists that are usually drawn together to account for the history and development of crowd theory. This oversight is all the more remarkable given the long history of concerns raised by bad behaviour at fairs, and how much legislation (in England and Wales at least) was introduced to address concerns about the detrimental effects of crowds on the moral fibre of the general population. Harrison notes how the general trajectory of fairs was caught up in these moralizing concerns that positioned fair-goers as representative of more widespread worries in C19th and early C20th which characterized the masses as unruly, drunken, illiterate, disobedient, and generally dangerous to social order. "It was fairs, increasingly given over to amusement rather than trade, that represented the quintessential 'dens of iniquity'."13 [Fig 3]

One strand of Harrison's work is to account for other discourses that read crowds as a neutral or even positive consequence of the development of industry and urbanisation; he traces the emergence of various strands of terminology and its overtones (from 'mob' to 'audience'). Despite the homogenizing tendencies of crowd theory and popular opinion, he argues crowds could be a source of potential good: 'The susceptibility of crowds to description as one homogeneous entity gave the possibility for claims of passionate social unity and cohesion around crowd events. ${ }^{14}$ Similar, more specific 
counter-narratives can also be found: social historian Hugh Cunningham's essay on 'The Metropolitan Fairs' opens with reference to Sir William Harcourt (British Home Secretary, 1885), who “ordered the Metropolitan Police not to interfere with steam roundabouts, 'these innocent amusements of the poorer classes... even if such amusements are presumed to constitute unlawful fairs with the Police Acts.' This deliberate refusal to use the power of the law against fairs contrasts strongly with official policy in the early part of the century when respectable minds saw in the metropolitan fairs a nursery of crime and a hotbed of vice." ${ }^{\prime 15}$ In their account of Blackpool, a sea-side resort in the north-west of England, historians Gary Cross and John Walton observe by the late nineteenth century how the crowd had become 'an object of good-humoured interest rather than fear', and was described as playful, orderly, rational, and good-natured. ${ }^{16}$ The Bishop of Manchester (many of the working class holidaymakers and day-trippers would travel to the resort from Manchester and other Lancashire mill-towns) was even moved to pen an introduction to the 1924 Blackpool Official Guide, noting how "Blackpool is rendering a really great service to the country by its ample provision of jolly and wholesome amusement."17

\section{The 'Playful Crowd' and Points of View}

Although Cross and Walton's work provides further counter-narratives that paint the crowd as a benign entity, it is their particular definition of a "playful crowd" that is more instructive in the context of this article. They are at pains to distinguish the crowd of their attention from crowds doing shopping, or at political rallies, for example. As they explain:

As sites of outdoor spectacle that invite crowds to interact with each other and with the sites themselves, to participate actively as well as to gaze and listen, to move, 
mingle, compete for attention and put the self on show... [the crowd's] pursuits were distinctly complex - seeking the novel as well as the nostalgic... And, in their inherent structure as artificial, but relatively open environments, they created a flowing, even potentially promiscuous, crowd that required special efforts to regulate and control. ${ }^{18}$

Cross and Walton studied the emergence and development of amusement parks at Coney Island and Disneyland (both USA), and Blackpool (UK). ${ }^{19}$ There are some significant differences between amusement parks and the travelling fairgrounds that are my focus, in particular concerning the more homogenized overall control exercised over the former (both in terms of the design of the environment itself — rides, queuing protocols, and overall theme- as well as physical and financial control over who enters: in contrast to amusement parks, there is no entrance fee for a travelling fair). Despite these caveats, the playful crowd has much to offer a study of fair-going crowds, particularly concerning the complexity of pursuits and movement within the crowd, and the interaction that is noted between the crowd and the sites themselves. It is around these two interlinked concerns that much crowd theory fails to find any purchase on the fairground situation.

As already mentioned, analysis of fairground crowds is surprisingly sparse given the widespread occurrence of fairs and the widespread worrying this has generated across countries and centuries. Descriptions of fair-going crowds tend to follow the naturebased metaphors common to all crowds. For example, an article in The World's Fair in 1908 stated how at Oxford St. Giles' Fair “a multitude... circled... [r] ound and about [the] attractions... The crowd was like some great river clotted with matter, twisting and turning between its two banks as best it could. There was no coherent plan or purpose to its movements; the people simply swirled to and fro, eddying backwards and 
forward". ${ }^{20}$ [Fig 4] The World's Fair is still in publication, describing itself as the weekly newspaper for travelling showmen and the funfair industry. Its regular reports on UK fairs follow a highly formulaic style, where the opening short paragraph will nearly always describe the weather and the size of the crowd, conflating these two phenomena as if they were a combined natural occurrence that acts as a barometer for the success of the fairs. This is not to deny the link, as the terrible weather for the Hopings in 2012 demonstrated only too clearly. [Fig 5.]

The corollary of this tendency to homogenise and naturalise the crowd is to reduce discussions of fairground architecture to considerations of the rides and attractions to aesthetic or technical objects, exemplified in the approach taken by architect David Braithwaite in his 1968 book Fairground Architecture, which remains the only substantial publication on this subject. ${ }^{21}$ A similar focus typifies legislative and quasilegislative concerns with crowd safety at fairs, where governmental and industry bodies address the issue by reducing it to ride-safety. (The fact that everyone is concentrating on the rides also distracts attention away from the ambiguity of the locus of control that is asserted over the fairground crowd.) One rare exception is an aside in the most recent "Review of Fairground Safety" undertaken for the UK government in 2001, known as the Roberts Report, which notes in passing that 'Other possible sources [than a major incident of catastrophic ride failure] of multiple fatalities are fire in enclosed structures or crowd behaviour... One study into public safety has been carried out at Pinner Fair, and this led to changes in layout and organisation of the site. ${ }^{22}$

These parallel tendencies are arguably perpetuated by the point of view of the researchers or commentators, who survey the fair from a position safely removed from 
any involvement with the fair-going crowd itself. Despite this criticism, the popularity of riverine metaphors is due in part to the extent to which they capture the experience of being in a playful crowd. There, we undoubtedly experience a difficulty of maneouvering against, through or out of the unfocused mass of other people. Different members of the crowd can by turns give in to its flow, and then assert their own agency before succumbing again. Philosopher Susan Buck-Morss has noted how the perception, for those outside the crowd such as the bourgeoisie, that crowds are compact, is belied by the experience (and agency) within, where according to Walter Benjamin "the dialectical opposition between individual and mass is abolished. ${ }^{, 23}$ Philosopher and literary critic Mikhail Mikhailovich Bakhtin makes a similar assertion in his well know work on Carnival, which "is not a spectacle seen by the people; they live in it, and everyone participates." 24 Consequently, as well as using these riverine metaphors, where it remains tricky to distinguish or anticipate attraction or action beyond the broad flows of the crowd, I would suggest it would be possible to expand the cacophonous experience of the fairground soundscape to provide a better metaphor. Cacophony allows for the possibility of understanding or isolating components of this noise and for these to affect behaviour accordingly.

My concern is thus to alter the point of view from which fair-going crowds have been regarded, in ways that are neither simply symbolic nor epistemic (allowing various different perspectives). Taking up the promise and challenge of the playful crowd, I propose that a related attitude can allow a more appropriate theory for fairground architecture and crowds to be put forward, one that situates the heterogeneity of participants and activities not as epiphenomena of a homogenous crowd contained by a surrounding, separate architecture, but that operates with this heterogeneity at an 
ontological level. As Cross and Walton's work suggests, the (playful) crowd and its environment needs must be approached in its complexity, such that its situation does not have to cohere or be synthesised into a neat whole, and that mutual antagonisms or contradictions can be accommodated.

This situation lends itself to discussion as an 'assemblage', and the analysis that follows is informed by assemblage theory. The notion of assemblages can provide a conceptual tool that allows us to approach the fair as a radically plural thing, maintaining the complexity that Cross and Walton note. Assemblage theory draws upon the work of Giles Deleuze and Félix Guattari, for whom an assemblage was "a multiplicity which is made up of many heterogeneous terms and which establishes liaisons, relations between them". ${ }^{25}$ Important in assemblage theory is the maintenance of this heterogeneity, such that the components that make up any one assemblage retain their autonomy, and can be understood to be simultaneously active in other assemblages. At the fair, the complex and heterogeneous connections between bodies, spaces and objects, rides, symbols, information, social mores, noise, music, smells and so on are 'assembled,' and become disassembled, in multiple ways. Understood as such, the fair can never be totalized. Reflecting on this point within the specific context of crowd theory, social theorist Andrea Brighenti stresses the importance of approaching the multiplicity in a conceptually distinct way in order "to focus on the point [at] which the 'many' stops being a sum of discrete entities and acquires its own status, not as a unity, substance, or group, but as a movement, operation, or act. ${ }^{, 26}$ With these remarks as a guide, the assemblage that is the fairground can be approached, with particular attention paid to the connections between fair-going crowd and fairground architecture. 


\section{fairground crowds and architectures}

"If they are to assemble and act, crowds need space, which is given a shape and contours by the representational use it is put to. Places are created to receive the masses - cathedrals and stadiums, for example — and to have the desired effect on them."- Serge Moscovici ${ }^{27}$

Hull Fair, where figure 6 was taken, attracts around half a million visitors each year. I want to develop an account of this experience that can hold on to the sensation of the playful fairground crowd, complete with its cacophonous soundscape and characteristic smells. To respond to this complexity, I will follow a concept developed from Deleuze's notion of assemblage by Manuel DeLanda as a meshwork diagram, appropriate for these types of complex structure or situation. Within such an account, DeLanda highlights "intercalary elements", a special class of operators that bring about connections between "heterogeneous elements" or ingredients, and that produce “interlocked heterogeneities" that stabilise the assemblage's patterns of behaviour. ${ }^{28}$ As Brighenti emphasized, we must not take this stabilization for stasis, and in the fairground-architecture-crowd assemblage the potential, simultaneous involvement of its constituent entities in many different assemblages can be grasped.

How to bring this to the hustle and bustle of the fairground crowd? DeLanda gives catalysts as one example of "intercalary elements", and coincidentally, Canetti describes the formation of crowds in similar terms, as a kind of crystalisation. Indeed, he identifies the significant role played by "crowd crystals": these are "the small, rigid groups of men [sic.], strictly delimited and of great constancy, which serve to precipitate crowds. ${ }^{, 29}$ Canetti goes on to emphasie that these can be small in number but that they must be constant and recognisable, familiar: "people must know what they are for". ${ }^{30}$ With rather polite examples including an orchestra and a royal court, Canetti 
argues that a crowd crystal is composed of individual entities, each of which have their own separate functions and which can seem — from within — to be indifferent to each other, but to the outside observer "appear as identical parts of a single unit". 31 To Canetti's general designation of "crowd crystals", a good deal of detailed terminology and analytical rigour can be added by borrowing from the work of sociologist Erving Goffman, particularly his study of Behaviour in Public Places. ${ }^{32}$ However, both Canetti and Goffman work almost exclusively with people and their interactions, and Canetti in particular offers scant consideration of any broader spatio-material settings. ${ }^{33}$ Goffman explicitly concentrates on face-to-face, or "immediate", interaction between small groups of individuals, although he does touch on the connections between these and "social occasions" which he defines as "a wider social affair, undertaking, or event, bounded in regard to place and time and typically facilitated by fixed equipment." ${ }^{34}$ The responsiveness offered by assemblage theory to the roles played by a much wider range of elements than Goffman and Canetti signals its potential as a guide in this more expansive approach to the fair-going crowds and architectures.

There are other aspects of Goffman's work that must also be extended to respond to the fairground situation. When he admits "the possibility that the same physical space may be caught within the domain of two different social occasions", and that this might lead to "potential or actual conflict between the sets of regulations that ought to govern", 35 he is taking the difference not only to be behavioural but also temporal: two different situations that take place at different times. However, the fairground is crowded with examples of different social occasions taking place simultaneously within the same physical space. (Moreover, with street-fairs, the overlap between the everyday and special occasions is also played out simultaneously, as the familiar environment and 
urban fabric of the setting is made strange by the arrival and positioning of the fairground architecture, even when the everyday activities are determinedly maintained.) [Fig 7] An approach informed by assemblage theory supplements Goffman's work, paying greater attention to the spatial and material characteristics involved. It also extends Canetti's understanding of the crowd crystal to include the roles played by the fairground rides and attractions. These can be understood to operate singly, in clusters, in networks, and across the 'whole' fair. This is not to explain away the polysensory pushing and shoving that we experience while in the fairground crowd, either physically from the various bodies that surround us, or indirectly from the visual, acoustic or olfactory calls we receive from the environment.

Rides are not taken here as a simple replacement for the human groups that Canetti notes, but can begin to be read as an assemblage that combines the ride as mechanical object with other cultural associations (promoted by decoration and applied artwork that draws on tradition and contemporary references such as the latest films or pop-stars, and loud music with particular cultural reference or resonance), as well as being animated by the amplified patter of "barkers," "spielers" or hawkers — to whom I will return later - all of which are intended to affect the dynamic of the fairground crowd, to draw the general crowd towards particular rides, and of course to persuade this interested group to become paying customers. ${ }^{36}$ Without suggesting that an initial focus on crowd crystals means that they are instrumental in dictating crowd behaviour, ${ }^{37}$ it is interesting to consider how varied are the situations where fairground crowd crystals operate when comparing the three particular fairs introduced earlier, in order to develop an approach within which more detailed attention to the fair-going crowd can be undertaken. 
Returning to the general layout plans show in figure 2 with these terms in mind, a hierarchy can be observed within the overall layout of the rides at Hull and the Hoppings, with major and minor avenues organizing major and minor rides. The simple axial layout at the Hoppings encourages punters to promenade around a there-andback circuit taking in everything, whereas the grid at Hull, with avenues and frequent decision points — go left, straight, turn right—provides punters with more options (and therefore requires the crowd crystals to work harder to attract and sustain a crowd of customers). By contrast, in street fairs such as Ilkeston navigation is much more complex for both locals and visitors, operating much more with differentiated crowd crystals that act as attractors pulling crowds into peri-urban and overlooked spaces such as back-street car parks and left-over spaces within the town. These are connected through the emblematic town center-the market square, complete with Town Hall, Library and Church — that also hosts prime fair real estate. Each of these crowd crystals develops a distinct character, repurposing existing urban form into the temporary architecture that bounds this fairground. [Fig.8, Fig.9]

In all these surroundings, the role played by 'crystals' is significant, but not the only determining factor in our experience of or in the crowd. Developing Goffman's observations on the simultaneity of differing occasions, it is typical to observe varying composition and dynamics of the fair-going crowd over the course of a day. When the fair begins to open, the punters are sparse and comprise of a significant proportion of grandparents and young grandchildren, or parties of young school children on an organized visit. After school, older children in uniform will pass through the fair on their way home, often returning as the crowd swells towards early evening, joined by the parents of younger children, or in larger 
groups of teenagers. As evening sets in fully, the crowd swells to capacity and is comprised mainly of teenagers and young adults. These changes in the demographics of the crowd are accompanied by clear shifts in crowd behaviour as well as simple density (becoming more boisterous and charged), as well as shifts in the performance of the crowd crystals in their precipitation of this crowd.

Overlaid with this build-up, other 'social occasions' can be witnessed, particularly where the fairground touches the everyday surroundings of the host town. At Ilkeston, for example, individuals or couples out shopping, for lunch, going to the bank or to catch a bus all pass by or through the fairground but do not involve themselves in its activity. Figure 10 shows the marked difference witnessed in front of and behind the stalls lined up along Walton Street, Hull, where simultaneously a lone cyclist makes easy progress behind the scenes while a dense crowd arrives at the fair as evening falls.

\section{“Guardians" \& "Involvement Contours" across the core-four}

To follow these different crowd dynamics in more detail, it is important to develop a more nuanced vocabulary alongside the broad role that is played by crowd crystals. Goffman introduces the term "guardians" to describe those whose "special job" it is to maintain the "normative stability" of a given situation. ${ }^{38}$ Restricting this consideration to the core-four rides, the role that their associated guardians play in crowd formation and behaviour is markedly non-homogenous, both between rides and over time. Regarding the latter, although my focus will be on differences that can be felt between afternoon and evening crowds, it is important to note that the dynamics of guardianship change over longer periods, both in response to new rides and changing idioms that 
redecorate existing rides, as well as to developments in crowd behavior. Cross and Walton suggest that in the face of ongoing change to guardianship systems and the 'stability' they attempt to maintain, "the crowd [finds] ways to adapt and resist, and to develop internal controls and restraints of its own." 39 Similarly, the Roberts Report introduced earlier noted how "Fair goers are said to be typically less disciplined and less willing to follow instructions than in the past. A few are said to be determined to get a thrill by whatever means_-including defeating passenger containment systems."40

Figure 11 sketches out these different guardianship dynamics across the core-four, and begins to illustrate the varied operations of each ride and crowd crystal. As Canetti observes, to the outside observer or punter the guardians appear to be parts of a single unit, although in fact they are non-homogenous: on the fairground, they are drawn from markedly different backgrounds that open onto the complex hierarchies operating within the communities of showpeople, and are involved in other non-material attributes of the crowd crystals. They range between members of very established families who have accrued rights over particular prime sites at each established fair, through to seasonal labour provided locally by what are know as 'gaff lads.' Whereas for the latter, their temporal involvement is short term, temporary and precarious, for the former it stretches over several generations, a lineage that marks significant cultural capital within the fairground community. However, it is principally the gaff lads that the crowd will encounter, as Duncan Dallas observes: "Since they collect the money from the customer they come into closest contact with the public. The gaff lads are not easily ignored. They dress, indeed, to attract maximum attention. ${ }^{, 41}$ Dallas' observations do not hold universally today, if they ever did: many larger rides now have separate paybooths, where members of the show families will usually handle the cash. The style of 
dress has also changed on larger, more established rides, where gaff lads increasingly wear some sort of uniform (from simple high-viz vests to more carefully branded clothing in the house style of the owners). These issues draw attention to the more complex economies of the fair, beyond the simple exchange of money for rides. When Dallas alludes to the gaff lads drawing attention to themselves, this was an element in the economies of power, desire and hetero-normative flirtation that operate alongside straightforward monetary exchange, an added enticement for both gaff lads (for whom working conditions are generally terrible) and groups of younger women in the crowd. (Flirtation with the latter adds a degree of tension with other punters, of course).

More nuanced discussion of these various economies, and their different manifestations across the core-four, can be undertaken by again referring to Goffman's analytical categories to provide a critical vocabulary. Taking a broad view, his work reminds us that everyone in the fairground crowd - guardians included — should be understood to be "immersed in a common pool of unfocused interaction," giving information about themselves, and receiving information from others. ${ }^{42}$ This casual phrase reminds us of the predominant riverine metaphors used to describe crowds, but in this particular situation it can be developed to draw attention to the operation of rides and guardians and the particular ways in which they attempt to attract punters. DeLanda focuses on the role of "far from equilibrium states" in the operations of assemblages: on the fairground this can be equated to behaviour at the furthest distance away from center of the crowd where the most apparently homogeneous crowd behaviour is displayed. In contrast, the most obviously heterogeneous mixture of groups and individuals, and the most distinct ranges of behaviours, is displayed furthest from this center, furthest from the equilibrium state, where the crowd makes most direct contact with rides and attractions. 
The crowd crystals - which include the guardians - play an important role in the interaction and exchange between these states. As Ian Trowell observes, "The aim for a showperson is to turn a crowd into an audience and then 'hold the audience with patter'. It is then necessary to convert the majority of that audience into paying punters, and then finally to ensure that these paying punters are satisfied punters". ${ }^{4}$

These holding patterns or conversions find a parallel in Goffman, who builds on the notion of a general "unfocused" exchange within the crowd at large, noting how this is supplemented by "focused" exchange within a sub-group. In terms that anticipate Assemblage theory, he notes how "there will be a fully shared basis of unfocused interaction underlying one or more partially shared bases of focused interaction. ${ }^{, 44}$ In other words, individual actors within the crowd always already partake in major and minor involvement in various exchanges simultaneously. Consequently, we should be prepared to mark a distinction between active and passive crowds - or sections of the same crowd - and between focused and unfocused interaction. Adding a further nuance, Goffman also distinguishes between full participants and onlookers or bystanders in a social occasion, and refers to an "involvement contour", defined as "a line tracing the rise and fall of a general engrossment in the occasion's main activity". ${ }^{45}$ In the particular situation just introduced, this involvement contour can be understood to reflect the effort required (or the success thereof) to hold the audience in a state far from the equilibrium of the general crowd, to persuade and maintain their presence at or on their ride. The material and behavioral arrangements around thresholds of the core-four reveal clear differentiation regarding how they direct crowd interaction and influence involvement contours. Although two of these rides are open (Twist and Miami) and two are enclosed (Dodgems and Waltzer), their thresholds conditions all modulate relations 
with the punters in the far from equilibrium state. The Twist and Dodgems have a low threshold, typically only one or two steps, whereas the Miami and Walter are set much higher at five or six steps. Concentrating on the latter two rides for brevity, they orchestrate very different guardianship behaviours and changing expectations of "normative stability." Figure 12 shows two different situations around the threshold of Anthony Harris' Waltzers on Ilkeston Fair. The first occurred during the afternoon when the crowd was thin and composed of parents with younger children (note the number of buggies/strollers). These 'active' bystanders are located mainly on the ground and lowest steps of the threshold, and 'allowed' to remain there by the guardians, who are positioned out of shot within the Waltzer itself. In contrast, three hours later as the crowd builds up into the evening, gaff lads work hard to persuade and cajole the active spectators and bystanders up to the top step of the threshold and even onto the grating (the narrow skirting adjacent to the moving Waltzer platform). Although this cuts off the little visual connection with the actual action on the Waltzer that is available to bystanders or the unfocused crowd, sufficient stimuli escapes (noise, lightshow, music, dry ice, screams and so on) for this crowd crystal to remain strongly attractive. The active spectators and bystanders now blocking the threshold seem to confirm the popularity of this (now invisible) ride, generating further interest.

Addressing more specific interaction, Goffman describes the conventions of comportment, clothing and interaction adopted by people in social occasions, and discusses how these are contingent upon and legitimated by that situation. Referring to "body idiom" and then more precisely to "involvement idiom" to acknowledge the more specific declarations this brings, Goffman argues that compliance within particular groups or sub-groups indicates that individuals therein understand and accept the 
normative regulations pertaining at a particular gathering. Beginning with face-to-face interaction, Goffman traces several levels of relationship between the particular acts observed within the subgroup, through to their involvement idiom, to "regulations" and social obligations that the group subscribes to and maintains. ${ }^{46}$ While Goffman's own examples lack the sheer noisiness, complex mobility and crowd density of the fairground, consideration of rides with the most complex and varied normative stability such as the Waltzer demonstrates how sub-groups can be distinguished by means of their "involvement idiom," such as a particular sub-cultural mode of appearance or an association with the music being played on that ride, as well as particular modes of behaviour. ${ }^{47}$ Different groups, and idioms, can be witnessed in different Waltzer cars, or between different Waltzers at the same fair which might be playing different genres of music, and have a different visual identity to appeal to different sub-cultural groups. While an involvement idiom may hold for a group in most situations, it needs must be put on hold when many of the rides are in action: or more precisely, the involvement idiom — and the behavioural "glue" it provides within a "normal" group setting — is required to adapt significantly when a ride such as the Waltzer or Twister begins because the speed and intensity of spinning movements that these rides subject their passengers to requires all but the most expert riders to concentrate on resetting themselves, individually, to this new and extreme motion. Hold on tight! Once underway punters become more accustomed to the ride's movement, and interaction can gradually be resumed: they are able to re-establish some version of their involvement idiom, inflected centripetally and centrifugally towards the car (for the Waltzer) and the crowd (for the Twist) respectively. 
In contrast to the involvement idioms accommodated by and associated with the Waltzer, which are shielded from the unfocused crowd by the active bystanders held in a far from equilibrium state on the threshold of this ride, the situation across the threshold of the Miami is notably different. Here, a significant part of the punter's experience involves spectatorship and performance, supported by the architecture of the ride and the role of the guardian. A large backdrop (typically decorated with large graphics and iconography suggestive of fast motion and/or sexual encounters) screens off other visual intrusions, focusing attention on the punters, while the guardian orchestrates participatory involvement between them, active and passive spectators, bystanders, and the crowd. The guardian calls out, encouraging punters to scream louder and the crowd to reflect back their excitement. Guardians also work to heighten suspense while the ride is 'held' at the top of its swing, and choreograph the rhythm of the ride to the accompanying music. Notwithstanding the 'spectacular' decoration that can be found all across the fairground, the Miami can be understood to be the most spectacular (stricto sensu) of the core-four. In contrast to other rides, where punters are caught up in the internal dynamics and complexities of the ride, the Miami explicitly establishes a spectacular relationship between punters and 'crowd' that provides an opportunity for punters to put themselves on show, to be arranged in a row, fully visible and facing the crowd, elevated and isolated as a spectacle, literally to be raised up above and to commune with the bystanders and crowd in a kind of ekstasis. The economy of this particular threshold condition is echoed, interestingly, in the police observation platforms found around and within Hull Fair [fig 13], a kind of Miami-in-miniature which similarly deploys a five-step-high platform to raise police into a position to surveil (and be surveilled by) the crowd. Whereas most of the crowd dynamics discussed thus far occur within a fairly horizontal zone, the architectures of both the 
Miami and the police observation platform offer a different relation based on an aerial view (over-view, sur-veiller or sur-vigilare): punters, or police, are moved out of and raised up above the crowd.

This more direct interaction between punter, active spectators and more passive bystanders has become further developed by more recent ride technologies, which have seen the introduction of large screens on some 'big-ticket' rides such as Air, shown in Figure 14. These screens relay various spectacles, showing a mixture of recorded footage (when the crowd is thin) and real-time action (magnifying the expressions of riders, or relaying the response of those in the process of leaving the ride). These various scenes can still be categorized according to some of Goffman's terms: in part, the screens take on some of the traditional roles of the guardian, speilers and showfronts in the crowd crystal discussed above, or at least support their working of the crowd; they also play to the call/response dynamic of the playful crowd, including the contracts of turn-taking in humiliation, excitement or fear by showing images of those waiting in the line (active participants), those 'survivors' coming off the ride (and seeing themselves do so), and playing images of the waiting, passive crowds and bystanders back to themselves in an effort to 'convert' the passer-by into an active spectator, or a hesitant attentive spectator into a participant (customer). Writ large on these screens, we can witness typical crowd dynamics from the fairground: exhibitionism, competition, thrill, terror or poise, turn taking, as well as the role they play in encouraging thrill enhancement, copying and positive social interaction across various categories of fairgoing public behaviour. 
These big-ticket rides are of such a size that they can take their place on the fairground as pure machines (vertigo machines, according to philosopher Lieven deCauter ${ }^{48}$ ), but they are also significantly unlike the core-four in terms of their technology, operation, and use of mediation. Indeed, the core-four enjoy—or rely upon—various layers of decoration, applied visual imagery and practiced guardianship in order to operate as crowd crystals, and this interaction — and the involvement contours that describe them - is characterized by a general physical proximity between the elements involved. In contrast, the involvement contours and their operation pertinent to Air are distended across the spaces of the fairground crowd, folding the far from equilibrium state occurring at the threshold of the core-four between crowd and crowd crystal back into the passive crowd. This supplements the generally prevailing cacophony and atmosphere with a specific visual reach and temporal complexity that the core-four cannot achieve. Indeed, Air also introduces a-synchronous temporal elements such as the replay of previous ride action (this could be, was, or could have been you) into the involvement contour.

Although big-ticket rides like Air remain an exception on the contemporary fairground because of this discontinuity of scales and times evident in their involvement contours, this example clarifies the distention of elements gathered by the involvement contours and the operation-at-a-distance of the intercalary elements across the fair-going crowd.

\section{Conclusion}

Returning this analysis of the complexity of fair-going crowds and architecture more forcefully to the vocabulary of assemblage theory, my assertion is that particularities of the fair-going crowd can be conceptualised more clearly by reading this intersection as 
an assemblage, an open whole, thus resisting the more prevalent tendency to homogenise the crowd, to reduce or dismiss it as a natural phenomenon. Goffman's conclusion comes close to this, and is worth quoting at length: regarding the behavior of an individual, he emphasises

the intensity of his [sic.] involvements, their distribution among possible main and side activities, and, importantly, their tendency to bring him into an engagement with all, some, or none present. There will be a patterned distribution or allocation of the individual's involvement. By taking the point of view of the situation as a whole, we can link the involvement allocation of each participant to that maintained by each of the other participants, piecing together in this way a pattern that can be described as the structure of involvement in the situation. ${ }^{49}$

However, Goffman's 'individuals' are human beings (distinct from the 'fixed equipment' he notes in passing), and the structure of involvement that he explains is underwritten by "social values or norms concerning involvement." 50 The analysis I have presented throughout this article helps to overcome the purely interactionist, face-toface framework of Goffman's work, opening the precision of his terminology (as well as that of Canetti and others) to the more complex materiality of the fairground situation, thus offering a different approach to the study of these crowds. As the empirical examples that I have discussed in detail reveal, the study of fair-going crowds requires a different, expanded understanding. There are far more complex social structures in play on the fairground (showmen, punters and local officials, although each of these three broad groups brings its own internal subdivisions and complexities), which are overlapping, partial or even antagonistic, and these are played out within, and with the involvement of, the complex materiality of the particular environment (material, technical, sensory, environmental, legislative and spatial surroundings of, and 
backdrops to, the rides) and socio-cultural associations (contemporary, historical or nostalgic).

Taken together, these expand the identification of participation units and bystanders, of fully- and partly-focused gatherings within these larger social occasions on the fairground, and begin to reveal the complexity of this particular fairground-crowdarchitecture assemblage. Of course, a bystander to, or spatio-material component within, one participation unit may be a partly- or fully-focused member or component of another, or many others, a situation that Deleuze and Guattari, and DeLanda, would describe as enjoying relations of exteriority, the simultaneous involvement in various assemblages. To paraphrase and then quote DeLanda, a fair gathers and guides (rather than fully organizes) the activities of many "social entities in a concrete physical locale, allowing them to interact and generate novel properties and capacities." ${ }^{51}$ This also goes some way to guard against accidentally rendering the crowd invisible by simply rereading it as a number of micro-events (or indeed by explaining it away as a fully understood whole, which Goffman seems to come close to).

Nevertheless, to hold the multiplicity together, some broader agreement or interest is required: in his simplest examples of this operation, DeLanda draws upon the smalltown market, where the interlocking of diverse people all with very different needs and demands is underwritten by the price mechanism. ${ }^{52}$ Far exceeding this pecuniary baseline, underwriting the coherence of the fairground assemblage is a set of more asymmetrical economies - financial exchange to be sure, but also economies of desire, spectacle, hard legislation and soft rules, and nostalgia — that draws the crowd and sustains it in its heterogeneity. As the various analyses here have demonstrated, the 
crowd-fairground-architecture assemblage holds together in a wide variety of ways, or thanks to a variety of 'intercalary elements' to stick with DeLanda's terminology.

There are certain provisos that should be added at this point: although the analyses presented here can be most easily grasped and organized across a nested series of scales (from face-to-face interaction within participation units and with guardians, rides, active and passive spectators, bystanders, to the unfocused crowd, the 'whole' fair, its host town and broader historical and geographic networks these also form part of), DeLanda emphasises that all scales are contingent and complex in assemblage theory. What is macro in one assemblage might be micro or meso in another. ${ }^{53}$ However, these discussions of scale mainly remain, for DeLanda, within a spatial register. The push of his analysis (at least in one direction) towards ever-greater abstraction is supported by examples that remain open to continued development over time. While he places great emphasis on turbulence and on far from equilibrium states, the timescales involved tend to be very long, relevant for the emergence of sedimentary rocks, biological species, and social hierarchies. With the crowd at the fairground, things change and flow very quickly by comparison (even if the fair itself can be positioned in a much longer history). ${ }^{54}$ Indeed one of the challenges presented by a fairground assemblage is that it forces consideration at much more immediate timescales — seconds, minutes, hours or days.

Despite these reservations, assemblage theory promoted the hybrid notions that I have drawn from in order to contest the ontological conceptions of totality that characterize much crowd theory. The particular approach taken in this article has been to account for the comminglings that occur at the fair by focusing on the events and liaisons rather 
than just the people or the objects involved. Reading the heterogeneity of crowds and materiality together, focused through the conceptual lenses provided by crowd crystals, involvement contours and so on, presents a different approach towards the study of crowds, precise but radically incomplete. Indeed, it is perhaps symptomatic of the fairgoing crowd, and the fairground, to outmanoeuvre attempts to account for crowd behaviour and dynamics, as much as it exceeds other more direct attempts to impose 'control'.

\section{Acknowledgements}

I must extend my warmest thanks to my colleagues Albena Yaneva and Łukasz Stanek for their generosity in providing careful and extremely useful comments during the preparation of this article. I would also like to thank the peer reviewers, whoever they were, for their robust and insightful criticism and suggestions, and to the editors of this special issue, Janina Gosseye and Cameron Logan, for their encouragement, patience and sensitive fine-tuning of the text. 

Figures

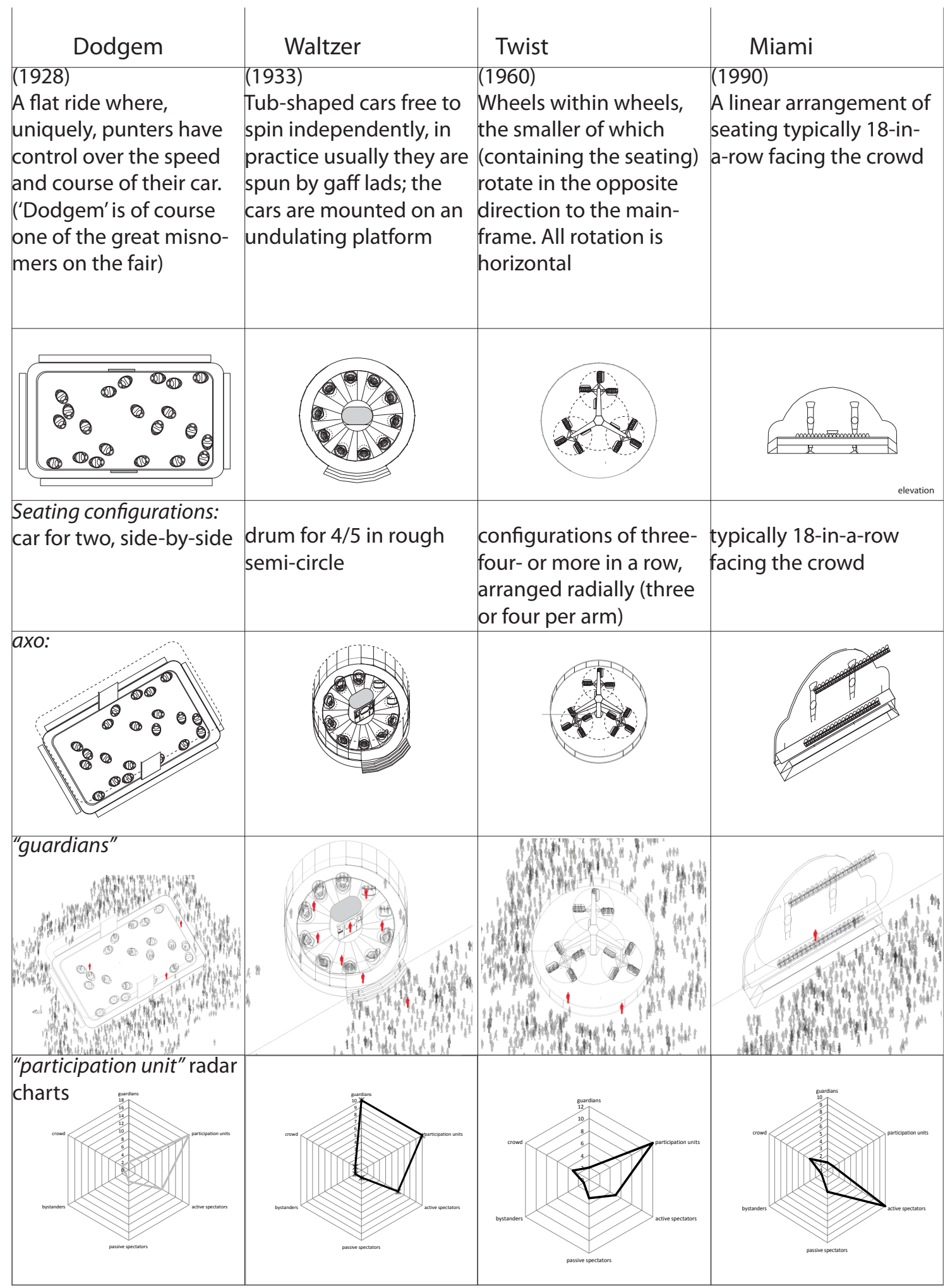

Figure 1. The Core-Four. Image by author 


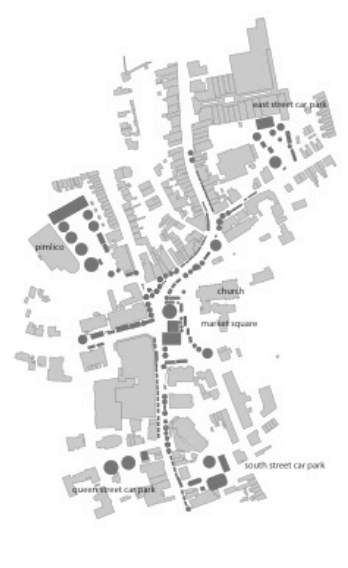

Illkeston Charter Fair, Derbyshire, UK

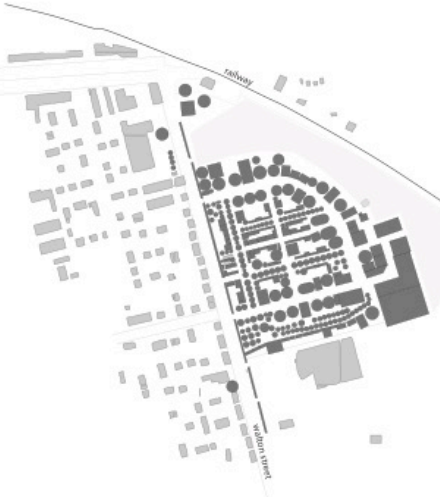

Hull Charter Fair, Yorkshire, UK

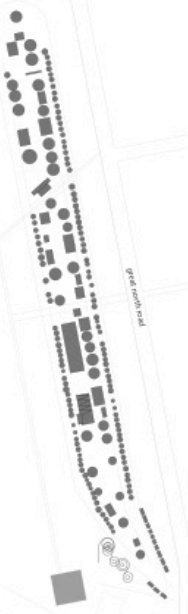

Newcastle "Hoppings" Fair, Tyne \& Wear, UK

Fig.2: (left to right) Layout plans for Ilkeston, Hull and Newcastle "Hoppings" Fairs. Fairground rides are shown in dark grey, permanent urban fabric in light grey. The fairground rides and attractions have to secrete themselves into the tight ancient street pattern of Ilkeston, a typical English market town with a central, hilltop market place located at the crossroads linking routes to neighbouring towns. Around the market place are gathered key civic and religious buildings - the main church, the town hall, library, police station and so on. In contrast, both Hull and the Hoppings are laid out on flat, open sites: Hull fair occupies a hard-standing, multi-purpose space that provides occasional car-parking and car-boot sales, and takes up a roughly triangular form bounded by suburban housing, a line of mature trees, and a railway line respectively. The Hoppings sits on a large grassed open space, and is bounded to its eastern side by “the Great North Road". Image by author. 


\section{ST. GILES'S FAIR.}

CAUTION AND REMONSTRANCE.

\section{To all Drunkards and Revellers, and to the thoughtless and imprudent of both Sexes.}

Y OU were told by the Oxford Board of Health on the Fifth of last December, (above Six Months before the Indian Disease had reached this City), that those bad been the greatest sufferers from Cholera who had been in the babit of indulging most freely in Spirituous Liquors, and that the babits of life should be regular and temperate. You were told by the Board the same salutary truths on the Twentyseventh of last July, when the Disease began to scatter Death amonost us. You are now told for ib third time, that Death and Drunkenness go hand in hand in these times of Epraemic Sickness. But you should consider the present Warning more weighty and more impressive than either of the other two, because it is given you after Two Months of sad and fearful experience. The Oxford Board of Health for the third time admonishes and intreats you to forbear and to abstain from all acts of intemperance and imprudence. Beware of late and long sittings, dancings, revellings, surfeitings, and such like. Beware of mixed, crowded, and unknown Companies in the distempcred atmospheres of Booths, Show Rooms, and Canvas or Boarded Apartments.-Infection lurks a long time in Stone and Brick Buildings; it is impossible to say how long it may continue in the materials of Wooden, Woollen, and Hempen inclosures; and who knows where the Booths of a Fair were last erected, or how many of a sick population may have been crowded within them? But especially beware of Drunkenness, for it has been found to bite as a serpent and to sting as an adder. Many who have raised the cup in merriment to their lips, have in agony lamented their excesses, and at their deaths have left a last legacy of warning to the Drunkard. Let all beware who think no cost too great for the purchase of present pleasure-Death smites with its surest and swiftest arrows the licentious and intemperate-the rash, fool-hardy, and imprudent.

By Order of the Board of Health,

VAUGHAN THOMAS, Chairman. WILLIAM THORP, Secretary.

September 1,1832 .

Fig. 3. St. Giles's Fair: Caution and Remonstrance (Oxford: Board of Health, 1832) facsimile copy (collection of the author). 
Fig.4. Oxford St.Giles Fair circa1904. Photographer unknown, National Fairground and

Circus Archive, William Keating Collection, Reproduced with permission of the University of Sheffield.

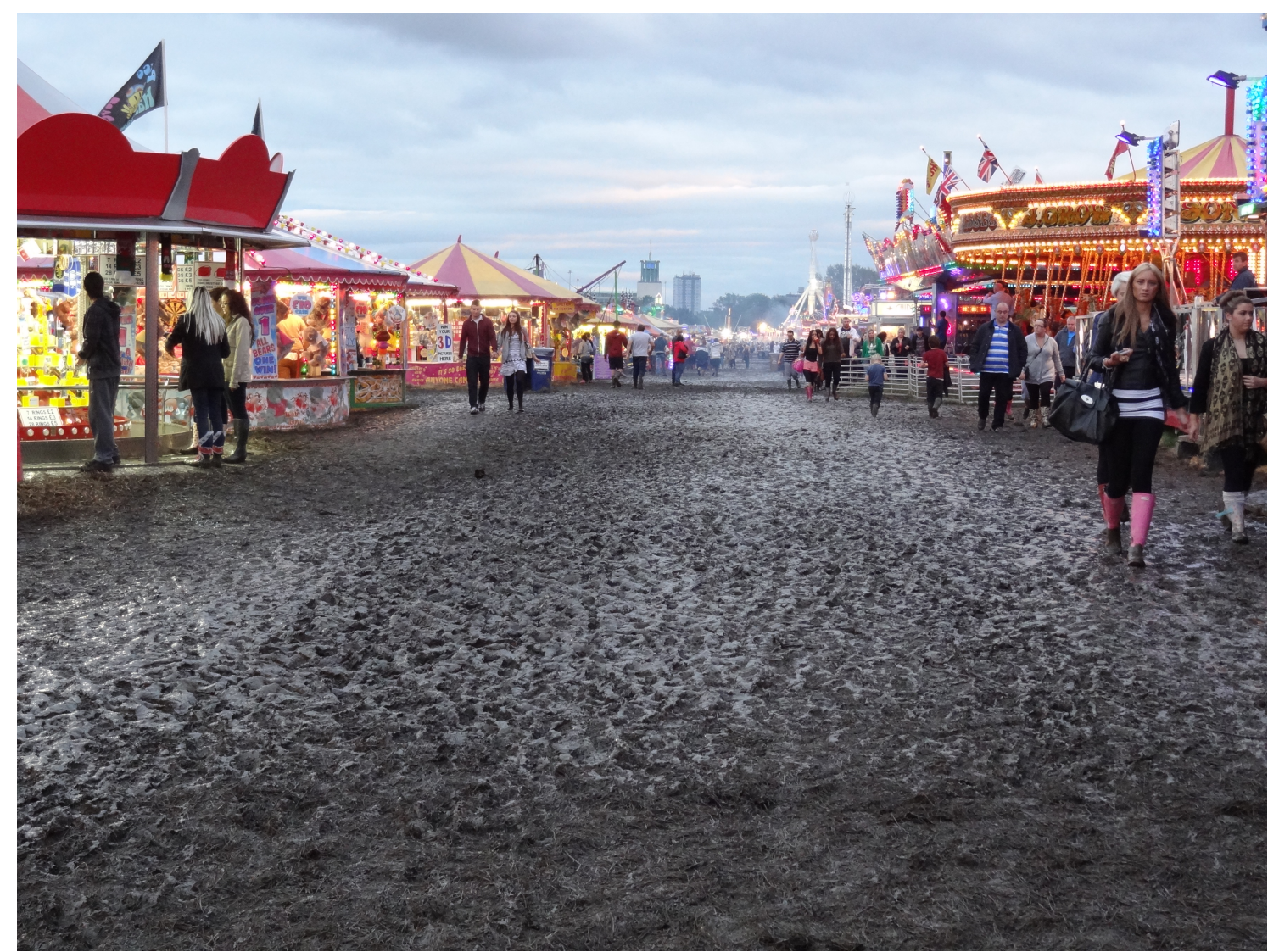

Fig.5. General view of the Hoppings in 2012, where days of heavy rain caused the

Town Moor to quickly turn to thick mud, with clear consequences on the public turn out. Such was the fallout from this event that the fair did not open in 2013. Photo: Ella Bridgeland. 


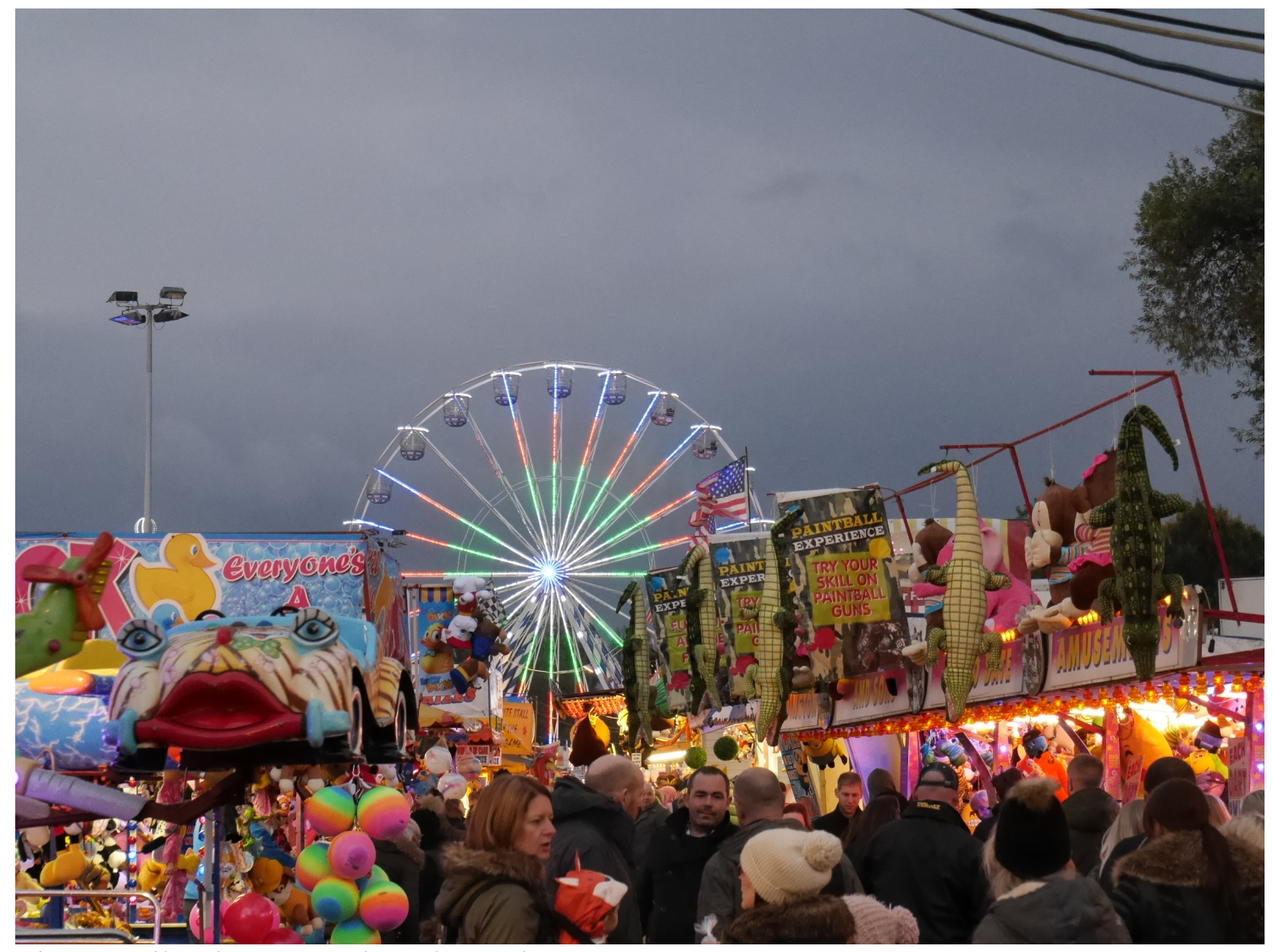

Fig.6. Hull Fair, 2010. Photo by author.

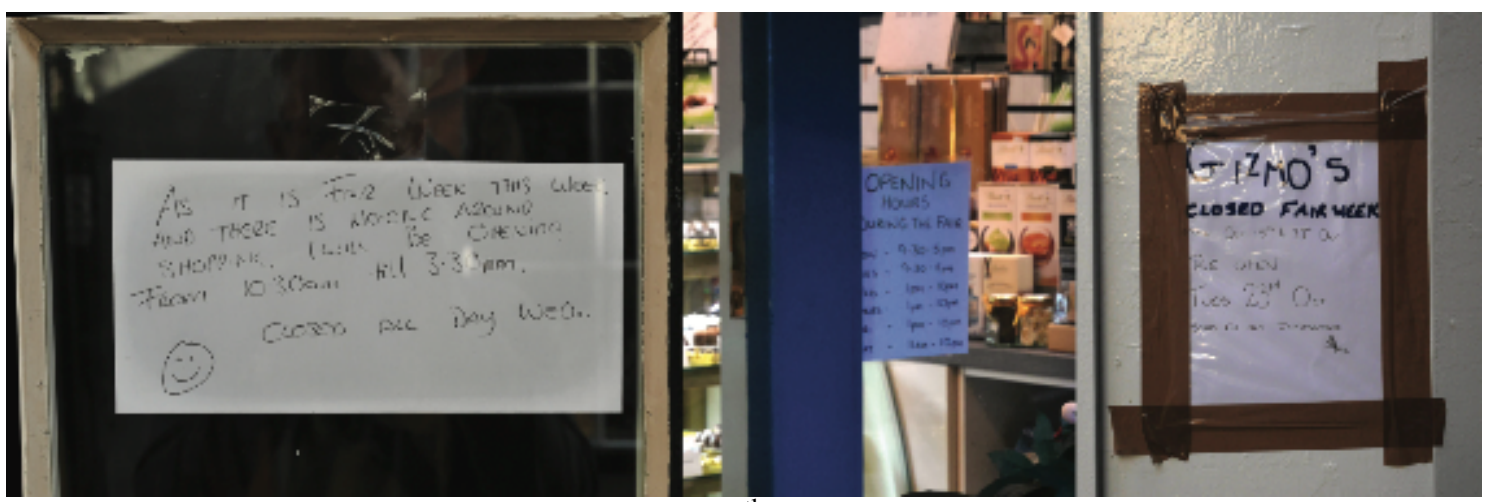

Fig.7. "As it is Fair Week..." Boston Fair, $4^{\text {th }}$ May 2016. "Opening Hours During the

Fair" and "Gizmo's Closed Fair Week" Ilkeston Fair, $18^{\text {th }}$ October 2018. Photos by author. 


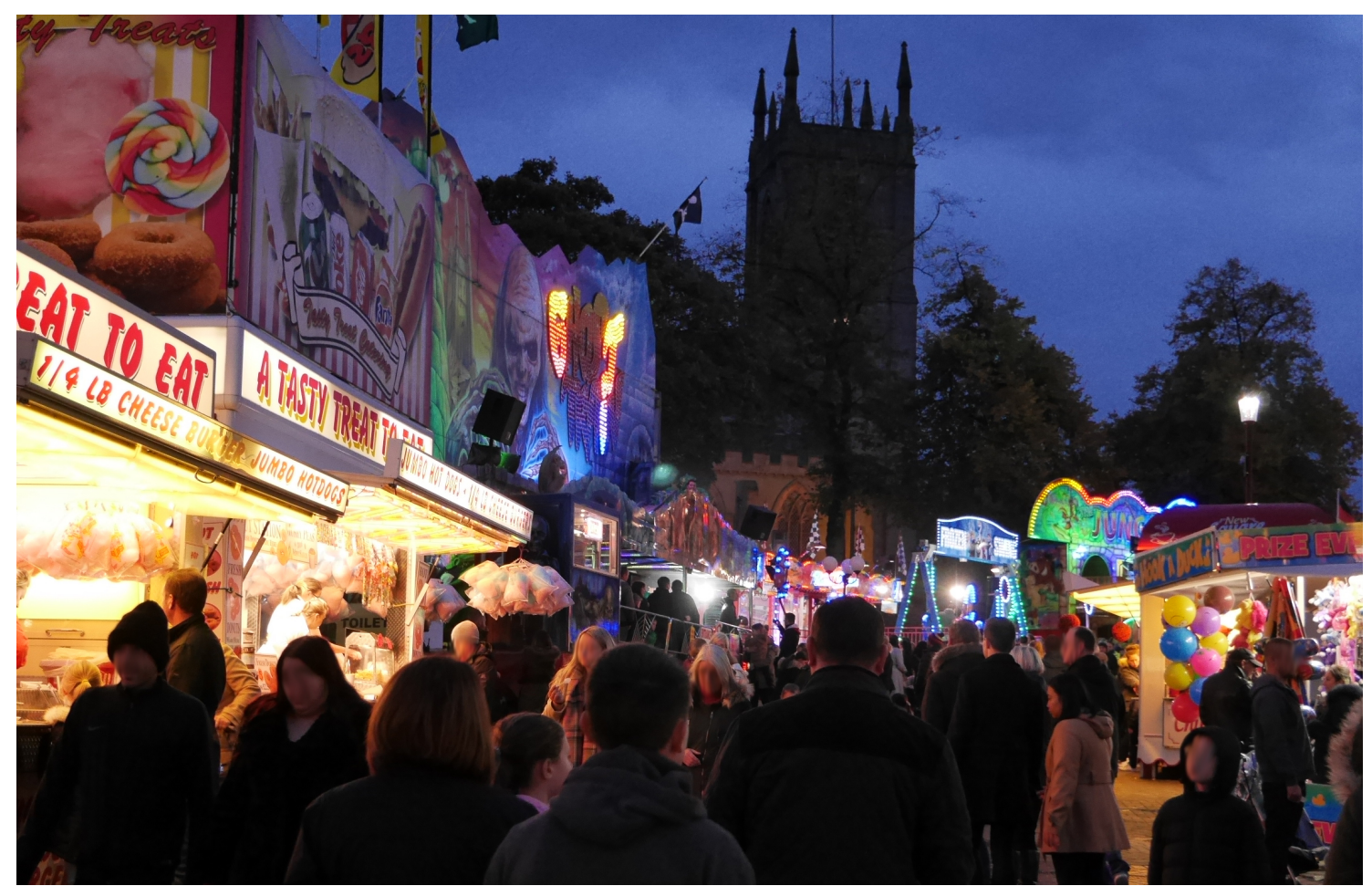

Fig.8. As evening falls, the fairground architecture increasingly dominates the familiar architecture of the town center. Here, St. Mary's church, occupying the hill-top site, can just be made out in the background of the fair, $20^{\text {th }}$ October 2016 . Photo by author. 


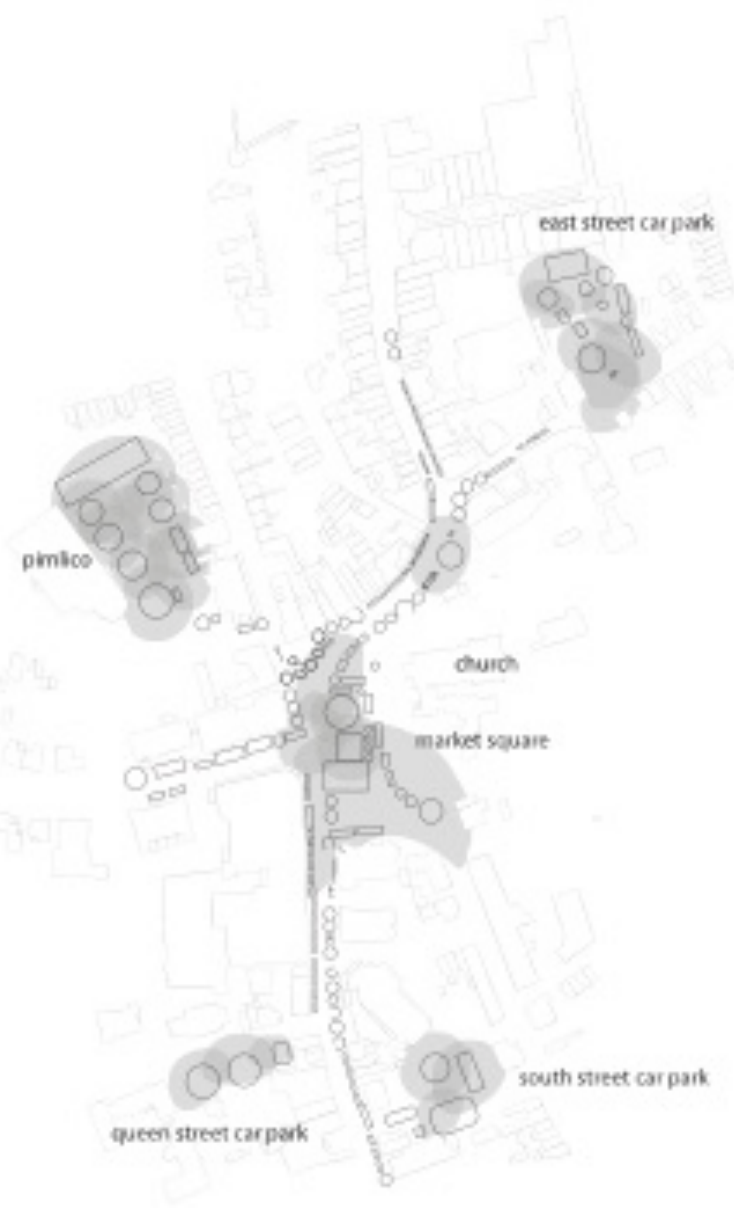

Ilkeston Charter Fair, Derbyshire, UK

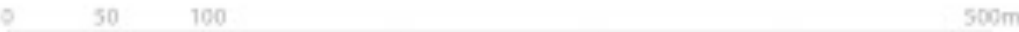

Fig. 9. Analysis of range and direction of the main crowd crystals at Ilkeston Fair. This disposition alters significantly the normal patterns and locations of activity within the town center. Image by author. 

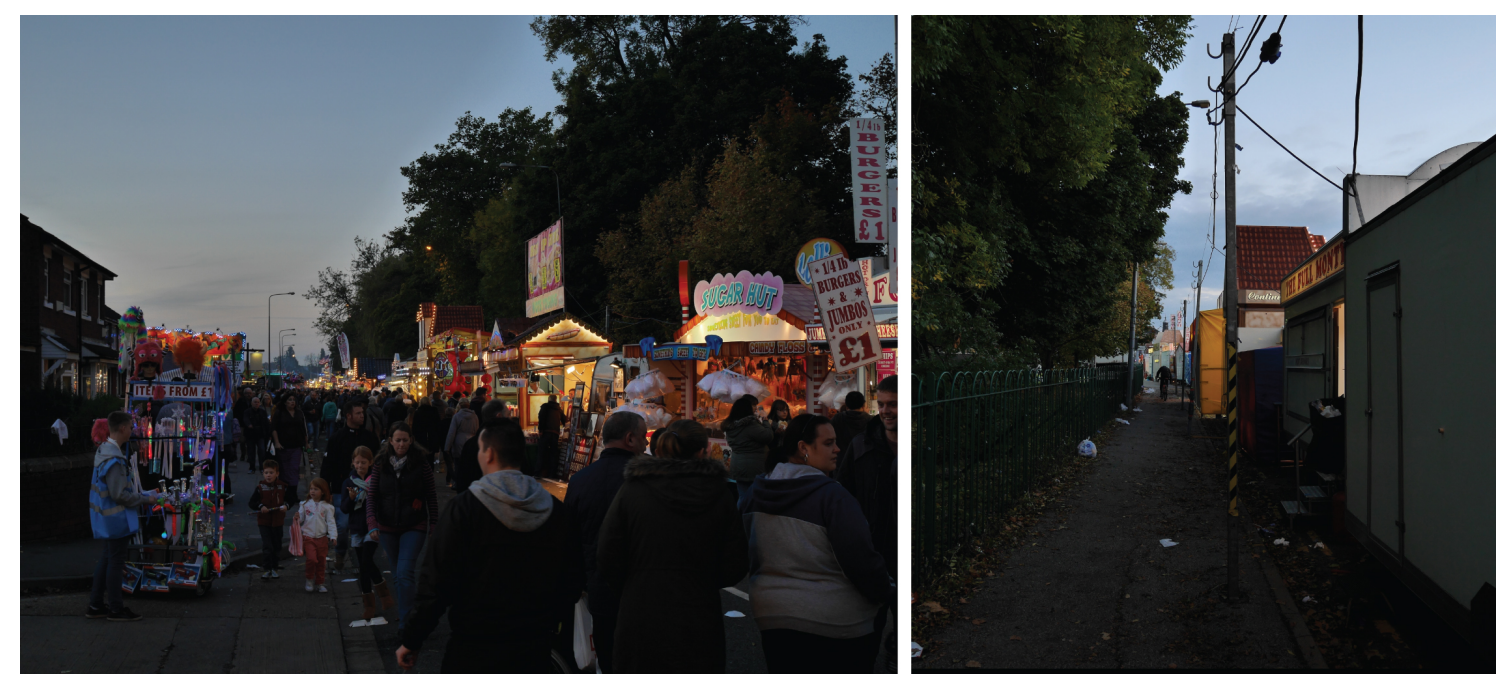

Fig.10. Hull Fair 2016, showing the simultaneous situation in front of and behind the stalls along Walton Street. Photos by author. 


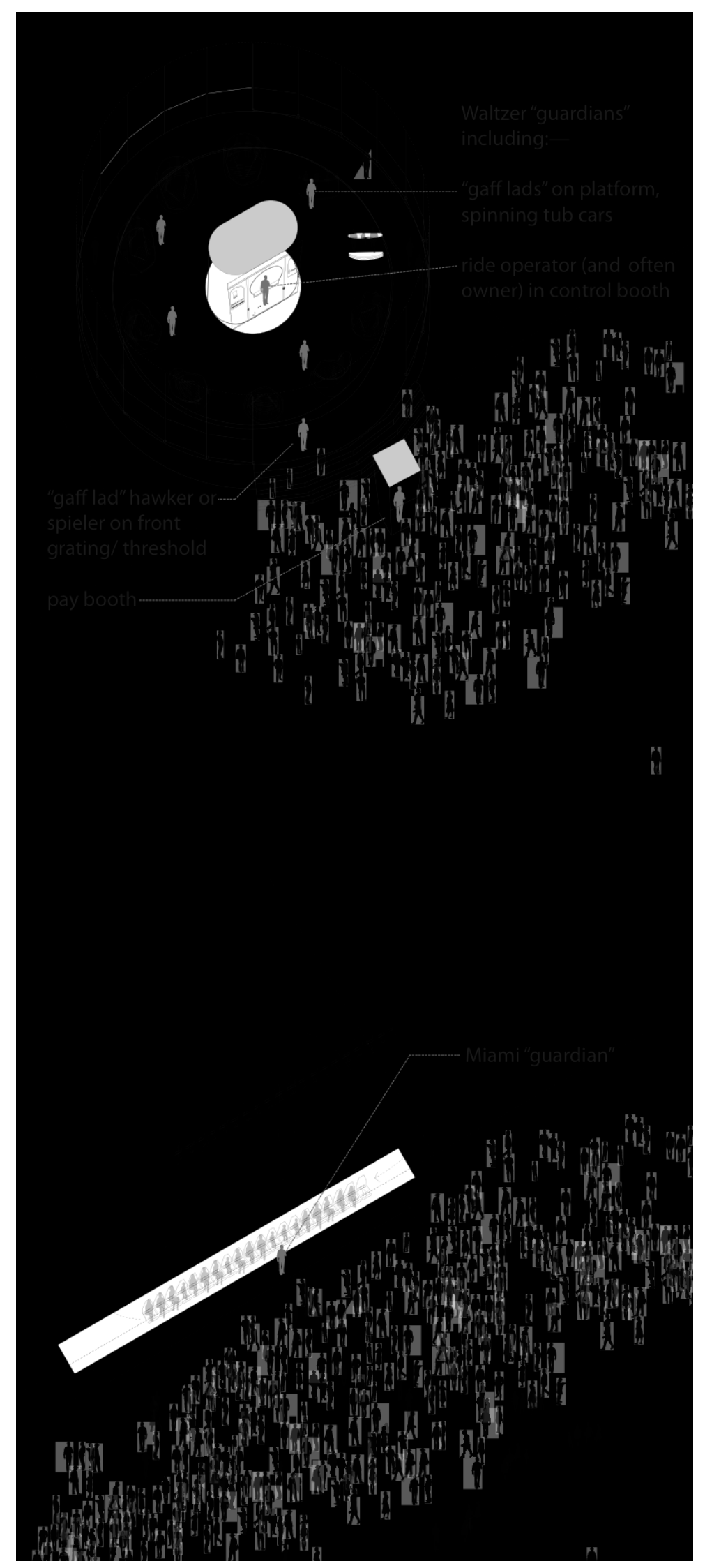

Fig.11. Comparative disposition and role of "guardians" between the Waltzer (top) and Miami (bottom). For those watching in colour, the guardians are shown in red. 
Within the core-four, the Waltzer is by far the most complex, with four or five different guardian roles (ride operator, usually doubling as DJ; the "gaff lads" who spin the tubs; a front of house guardian in the pay booth who takes the money; and hawkers or barkers often standing on the front steps or even in the passing crowd to drum up trade. The Miami guardian oversees the safety restraints and passenger containment systems such as belts or safety rails as punters take their seats, and then during the ride their main input, if any, is to whip up screaming, as it the case on the Twist. The Dodgems have a different degree and dynamic of interaction between punter and guardian (usually the latter intervenes either when punters get stuck - usually the steering mechanism overwinds - or when aggressive driving breaks out, and "dodging" is replaced by repeated, direct collisions).
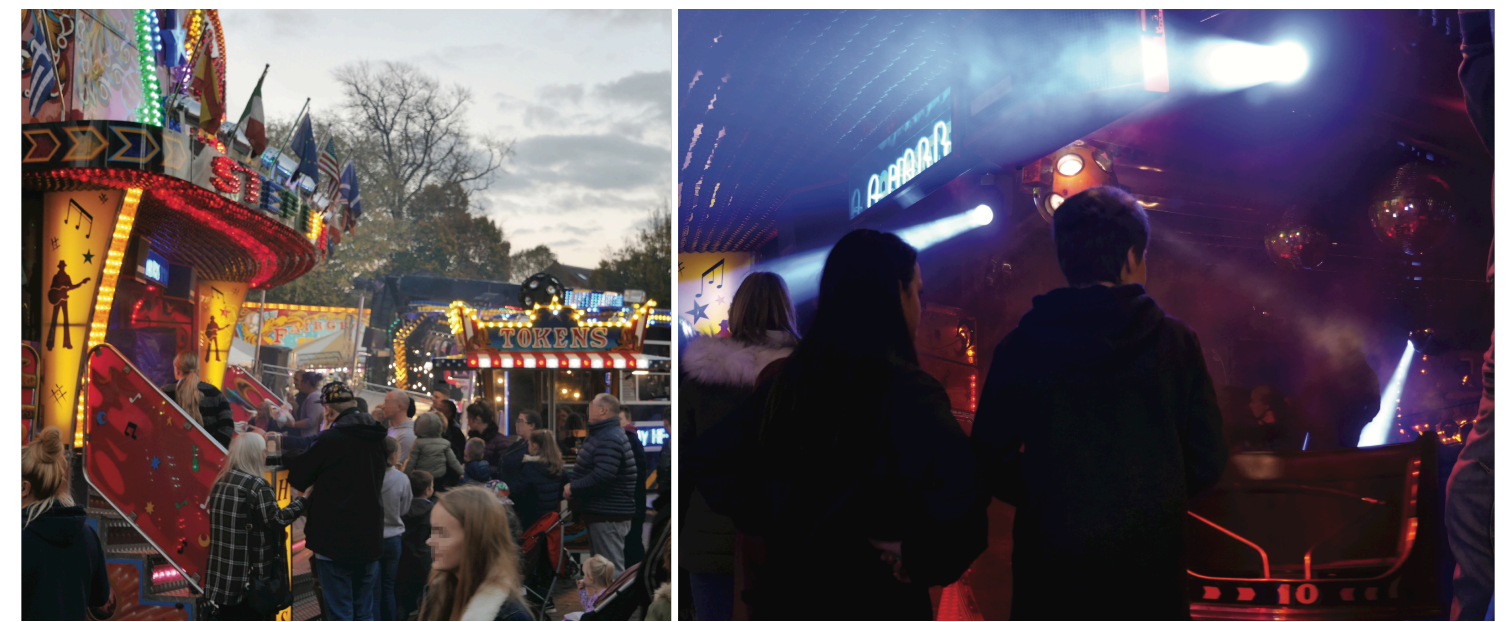

Fig.12. The threshold of Anthony Harris' Waltzers on Ilkeston Fair, 2018, showing the increasing degrees of encroachment —or the active manipulation (tightening) of the "involvement contour"- encouraged by the gaff lads as afternoon gives way to evening crowds. Photos by author. 


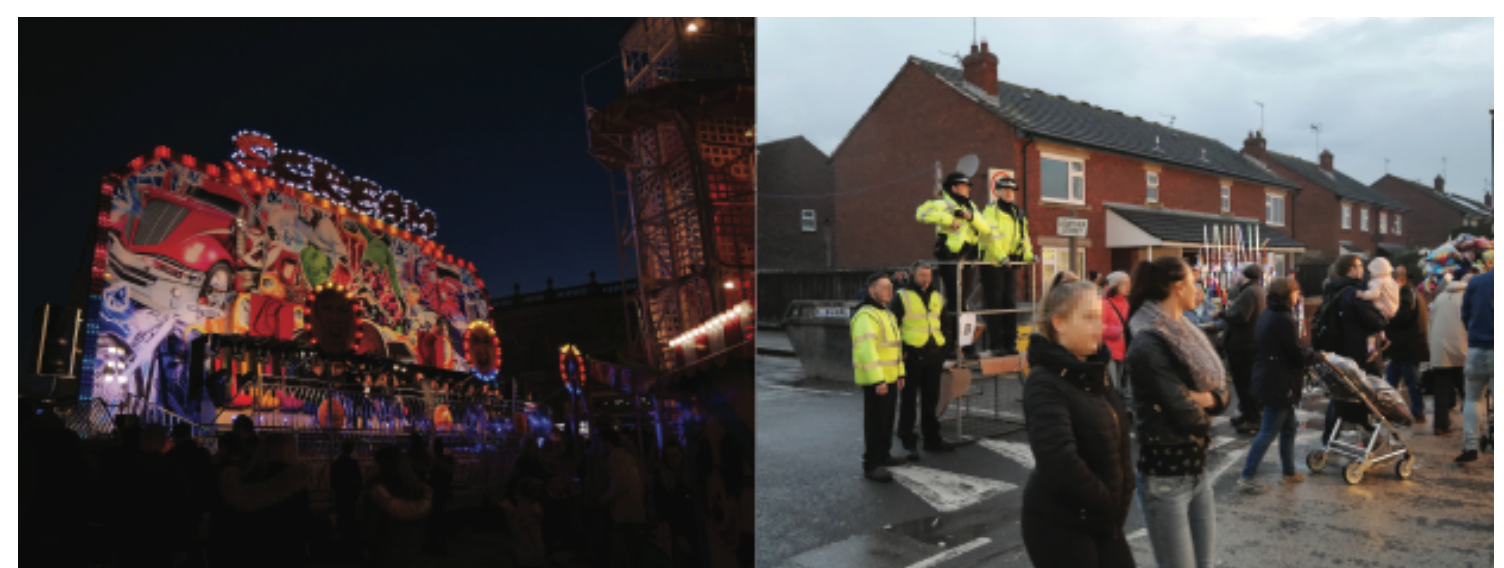

Fig. 13. Anthony Harris' “Scream” Miami (Ilkeston Fair, 2018) where a single guardian ensures punters are correctly fastened in and takes payment; and police observation platforms at Hull Fair (2016), a stripped-down reflection of the Miami. When the Miami is full or close to capacity, the guardian's role changes, becoming more of an MC orchestrating interaction between punters and the spectators, bystanders and crowd. It is worth noting in passing that the extent of policing at fairs is really low compared to other crowded events such as political rallies, sporting (especially football) events, and even crowds at religious events. Photos by author. 

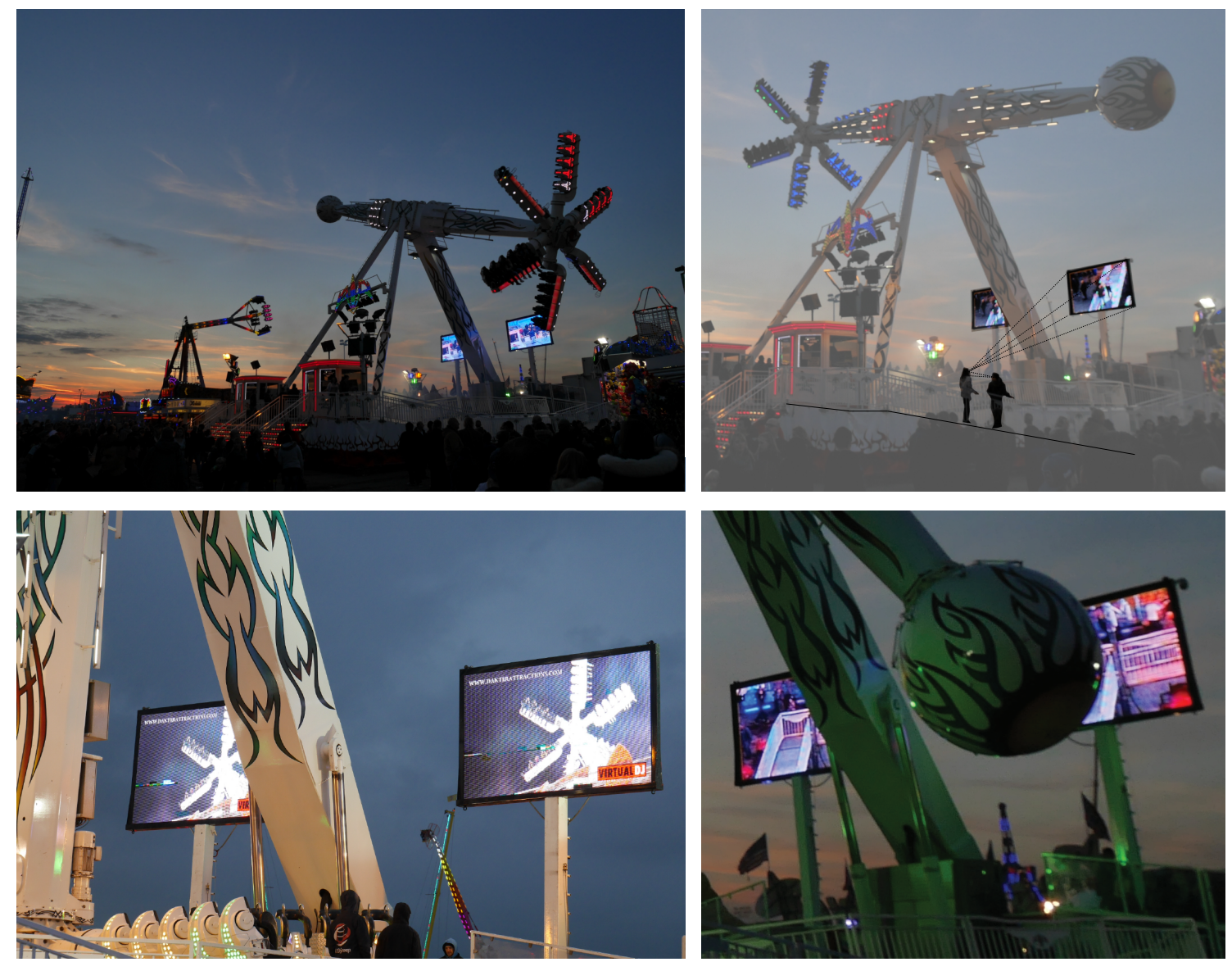

Fig. 14. Danter Attractions' "Air" at Hull Fair, 2015, 2016. Here, screens allow the

synchronic self-recognition for riders just disembarking (top right), or a diachronic recognition of self in others between those queuing, riding, or having just finished (bottom right). Screens also replay 'live' action sequences when the ride is at rest, waiting for the crowd to arrive (bottom left). It is also worth noting the machinic throughput of crowds, processed along a production-line provision of entertainment and thrill, with separate queuing, entry and exit routes to avoid clash of embarking and disembarking punters. This contrasts with the situation on the core-four (with the partial exception of the Miami), where entry and exit is across the same threshold, enforcing a physical encounter between about-to and have-just riders. Photos by author. 
1 William Kentridge, "Fortuna: Neither Programme nor Chance in the Making of Images," [1993] in William Kentridge, ed. Rosalind Krauss (Cambridge MA: MIT Press, 2017), 28.

2 Mark Harrison, Crowds and History: Mass Phenomena in English Towns, 1790-1835. (Cambridge: Cambridge University Press, 1988), 4.

3 Le Bon breaks up his study of organised crowds into heterogeneous crowds (subdivided into 'anonymous crowds' and 'crowds not anonymous' and homogenous crowds (political or religious sects, military or working castes, social classes etc): see Gustave Le Bon. "The Classification of Crowds" in The Crowd: A Study of the Popular Mind, [1895] first published in English in 1896 by London: T. Fisher Unwin: facsimile by Mineola, N.Y.: Dover Publications \& Newton Abbot: David \& Charles, 2002), Book III Chapter 1, 158.

4 This term was introduced, to me at least, by Owen Ralph, Editor of Park World, in a talk given at the National Fairground Archive, Sheffield, $31^{\text {st }}$ October 2014.

5 Following the Fairs Act 1871, which noted fairs to be "the cause of grievous immorality, and are very injurious to the inhabitants of the towns in which such fairs are held," more than 250 fairs across England and Wales were forcibly closed for the "convenience and advantage of the public."

${ }^{6}$ I am borrowing these terms from Elias Canetti. Crowds and Power. Trans. Carol Stewart (Harmondsworth: Penguin, 1973): although he is at pains to disrupt the binary contrast that is perhaps suggested by their introduction at the beginning of his book (and associated with "static" and "natural" situations respectively), the simplistic reading of two different modalities of crowd formation and behaviour is often repeated.

7 Trowell, I. (2017). 'The Fairground Noise' Politiques de communication, hors série 1,(HS), 209-241. https://www.cairn.info/revue-politiques-de-communication-2017-HS.htm-page-209

8 There is a useful survey in Andrea Mubi Brighenti, “Tarde, Canetti, and Deleuze on Crowds and Packs" Journal of Classical Sociology Volume 10 Issue 4, (November 2010) 291-314; For a broader discussion of the watery comparison in particular, see Jeffrey T. Schnapp, "Mob Porn," in Crowds, eds. Jeffrey T. Schnapp \& Matthew Tiews, (Stanford CA: Stanford 
University Press, 2006) where he surveys the dominance of the 'oceanic' symbolism that runs through writings on the crowd, as well as the influence of panoramic photography on the enlargement of this mode of thinking during the first half of the twentieth century.

9 David Roberts (summarizing Moscovici summarizing Gustave Le Bon), 'The Natural History of Modernity' in Elias Canetti's Counter-Image of Society: Crowds, Power, Transformation, eds. Johann P. Arnason and David Roberts (Cambridge MA: MIT Press, 1996), 28-9.

10 Canetti. Crowds and Power, 23.

11 Harrison, Crowds and History, 5.

12 See in particular Serge Moscovici, The Age of the Crowd: A Historical Treatise on Mass Psychology (Cambridge: Cambridge University Press, 1985), 122. Elizabeth Wilson, The Sphinx in the City: Urban Life, the Control of Disorder, and Women (London: Virago Press, 1991), 7. For an overview of these characteristics developed by mass psychology, see Stefan Jonsson, 'The Invention of the Masses: The Crowd in French Culture', in Crowds, eds. Jeffrey T. Schnapp \& Matthew Tiews, esp. 73. Moscovici does offer a rider on this tendency, noting how 'A society which is convinced of its own de facto and de jure stability is relatively tolerant of deviant and nonconformist movements.' Moscovici, The Age of the Crowd, 73. That is to say, crowds only become a concern (become a 'mob') when other pressures are felt.

13 Harrison, Crowds and History, 181. Despite the date range of his title, Harrison's work continues to engage with crowd tendencies through the C19th and up until studies in the 1960s (such as E P Thompson).

One specific example of the prevailing Victorian attitude towards the fairground iniquity can be provided by an article from the Leeds Mercury, dated $16^{\text {th }}$ July 1863: 'Thus for a whole week... have the streets been crowded, the public houses crammed, the pickpockets, sharpers, and showmen filled... Crowds of men and women... drunk, surging up and down the streets, gurgling round the entrance of the...beer-shops; 
pickpockets...unfortunate women...children struggling through the crowded booths...

witnesses of all the disgusting immorality, the ribald jesting, the cursing and profanity... and other nameless things, in which these fairs and feasts abound.' cited by Robert Storch, 'The Problem of Working-Class Leisure: Some Roots of Middle-Class Moral Reform in the Industrial North' in Social Control in Nineteenth-Century Britain, ed. A. P. Donajgrodzki (London: Croom Helm, 1977), 144.

14 Harrison, Crowds and History, 170.

15 Hugh Cunningham, 'The Metropolitan Fairs: a Case-Study in the Social Control of Leisure,' in Social Control in Nineteenth Century Britain, ed. A. P. Donajgrodzki (London: Croom Helm, 1977), 164.

${ }^{16}$ Gary S. Cross and John K. Walton, The Playful Crowd: Pleasure Places in the Twentieth Century (New York, NY; Chichester: Columbia University Press, 2005), 107.

17 The Bishop of Manchester, in the Blackpool Official Guide, 1924, cited by Cross and Walton, The Playful Crowd, 109.

18 ibid. 5. Concerning control, they go on to note 'The playful crowd was less threatening politically but more threatening culturally and morally.' ibid. 7 .

19 They also studied Beamish, an open-air 'living heritage' museum in the north-east of England.

20 Anon, 'Oxford St. Giles', in The World's Fair, 19 September, 1908, p.1.

21 David Braithwaite, Fairground Architecture (London: Hugh Evelyn, 1968). For an architectural theoretical review of this gap in architectural literature, see my 'Illusory Objects and Fairground Architecture.' The Journal of Architecture 20 no.2 (April 2015), $309-354$.

22 'Review Of Fairground Safety: Report to the Health and Safety Commission,' Prepared by: Paul Roberts (HM Principal Inspector of Health and Safety) Safety Policy Division, 02 August 2011, Version 1.2, Section 4.26. Available at http://www.hse.gov.uk/entertainment/pdf/revrep.pdf (retrieved 17th October 2011) 
In the UK, Health and Safety Codes pertaining to the travelling fair emerged officially in 1976, when the Home Office Guide to Safety at Fairs was published. This followed the transfer of responsibility for safety matters to the Health and Safety Executive (HSE) established under the 1974 Health and Safety at Work Act. This subsequently developed into the Code of Safe Practice at Fairs (London: Health \& Safety Executive, 1984), then the Fairgrounds and Amusement Parks: A Code of Safe Practice HS(G)81 (London: HSE Books 1992), and then the Fairgrounds and Amusement Parks: Guidance on Safe Practice HS(G)175 (London: HSE Books, 1997). These have been further developed following the Roberts Review Of Fairground Safety, 2011, cited here.

For another unusual example of research that focuses on the broader environment, rather than the individual ride, see Arwen P. Mohun, 'Designed for Thrills and Safety: Amusement Parks and the Commodification of Risk, 1880-1929,' Journal of Design History, Vol. 14, No. 4, Technology and the Body (2001), 291-306. Mohun makes a clear distinction between ride safety and the perceived safety felt by women in the crowd, with particular efforts made on the part of amusement park owners to ensure that "female clientele... felt protected from unpleasant or threatening social encounters, principally with single drunken or 'rowdy' men." ibid., 292. Mohun analyses the first generation of punters for whom what we'd now refer to as the Health and Safety lobby were a conscious or constituent part of a visit to the fair (and the distinction these punters made between industrial risk and injury they faced at work compared to the risks they faced in leisure activities.) As with Cross and Walton, her analysis focuses on amusement parks, rather than fairgrounds.

23 Walter Benjamin, Selected Writings, vol.3, 1935-1938. Howard Eiland and Michael Jennings (Eds), Edmund Hephcott et al (trans). (Cambridge MA: Harvard University Press, 2002), 129. Cited by Susan Buck-Morss, 'Compactings and Loosenings', in in Crowds, eds. Jeffrey T. Schnapp \& Matthew Tiews, 3B, 92.

24 Mikhail Bakhtin, Rabelais and His World, [1965] trans. Hélène Iswolsky (Bloomington: Indiana University Press, 1984), 7. 
Canetti opens his book on Crowds and Power by contrasting the comfort of the spectacle with The Fear of Being Touched, reassuring his readers that it is safe to follow him into the crowd: "It is only in a crowd that man can become free of this fear of being touched. That is the only situation in which the fear changes into its opposite. The crowd he needs is the dense crowd, in which body is pressed to body". 15 .

For an extended consideration of this dynamic of over-viewing the fairground, see my 'Spectatorship: The Panorama of the Whole', in The Fair Line and the Good Frontage: Surface and Effect, (London: Palgrave Macmillan Ltd, 2018), 83-103.

While acknowledging the influence he continues to have over work in this area, Peter Stallybrass and Allon White gently contest various of Bakhtin's assertions that the fair is a utopia, a pure outside, noting that it is "neither pure nor outside... situated at the intersection of economic and cultural forces, goods and travellers, commodities and commerce." Peter Stallybrass and Allon White, The Politics and Poetics of Transgression. (London: Methuen, 1986), 28-30. They link in other historians and theorists (such as Robert Malcolmson, E. P. Thomson and so on) who, like Bakhtin, maintain an implicit binary in their championing of the fair. "The fair is located on one side of a series of oppositions as 'popular', celebratory, grotesque, and its history becomes one of a transformation from 'licence' (i.e. excess) to 'licensed' (i.e. authorised), with the concomitant suppression of the 'unlicensed' fairs." 34. Similarly, we should only go so far with Buck-Morss, as sometimes the crowd really is a crush, and it removes or curtails the individual of any capacity for individual movement.

${ }^{25}$ Gilles Deleuze and Claire Parnet, Dialogues II, [1977] trans. Hugh Tomlinson, (New York NY: Columbia University Press, 1987), 69.

${ }^{26}$ Andrea Mubi Brighenti, “Tarde, Canetti, and Deleuze on Crowds and Packs,' Journal of Classical Sociology 10(4), (2010), 304-5.

27 Moscovici, The Age of the Crowd, 141.

28 DeLanda, A Thousand Years, 64, but making strong and sustained use of Giles Deleuze \& Félix Guattari, A Thousand Plateaus: Capitalism and Schizophrenia. [1980] Trans. Brian 
Massumi (London: The Athlone Press, 1987), 328ff. DeLanda acknowledges his debt to, and extension beyond, the work of Deleuze (indeed he concedes that his more explicit assemblage theory could be called a 'neo-assemblage theory' or 'assemblage theory 2.0 '. Manuel DeLanda, A New Philosophy of Society: Assemblage Theory and Social Complexity (London; New York: Continuum, 2007), 4, 30.

29 Canetti. Crowds and Power, 85. ibid., 85.

31 ibid., 465.

32 Erving Goffman, Behaviour in Public Places: Notes on the Social Organization of Gatherings (New York: Free Press, 1963). Goffman's work, by dint of its key or base-line ingredients (two individuals) can feel inappropriate or forced when taken to crowd theory. However, he did anticipate and address larger gatherings in public space, both formal and informal, and the level of detail he paid to the dynamics of attention and interaction put some broadly homogenising crowd theories under pressure. Goffman does actually suggest that 'a street market' could be a good example at which we could describe conduct in this context, “employ[ing] the structure of involvement... as one frame of reference." 193.

As many other commentators have remarked, Goffman's proto-assemblage theory approach lends itself to this kind of application. For example, DeLanda refers to Goffman's 'Assemblages and Human History' in Assemblage Theory esp. 27-30, and to Goffman's 'Interaction Ritual,' in Essays on Face-to-Face Behaviour (New York: Pantheon Books, 1967). However, DeLanda, and several other commentators who pick this up, focus on Goffman's analysis of critical points of embarrassment, as something of a turbulent, nonlinear dynamic that causes a conversation (or more broadly a face-to-face social interaction or gathering) to fall apart or destabilize. In contrast, my use draws more on Goffman's other work on face-to-face or "immediate" interaction.

For more critical readings of Goffman in the context of crowd theory, see Plotz who criticizes Goffman (along with Mauss and others) for granting too much import to the 
epiphenomena of more important or thoroughgoing social processes, something that Moscovici observes more gently. However, I would argue that it is precisely in this attention to a fuller range of ingredients in an assemblage that gives Goffman's approach traction.

33 A parallel oversight can be found in ritual theory: for a gentle criticism of this tendency, see Catherine Bell, Ritual: Perspectives and Dimensions (New York \& Oxford: Oxford University Press, 1997), esp. 139, 171: and Catherine Bell. Ritual Theory, Ritual Practice. [1992] (New York \& Oxford: Oxford University Press, 2009), esp. Ch.6 "Ritual Traditions and Systems".

34 Goffman, Behaviour in Public Places, 18. He also notes that immediate interaction is traditionally regulated by "public order" and "also matters that need not entail immediate contact between persons." ibid., 8. In a later work, Frame Analysis (Cambridge MA, Harvard University Press, 1975), Goffman's reading pays more attention to the context of human actions (physical setting, clothing, forms of discourse etc. with associated norms of behaviour), and how such actions are inflected by the 'frame' in which they take place.

35 ibid., 20. Goffman talks about public streets having a generally agreed public decorum that is occasionally interrupted or challenged by processions, fire engines, etc.

${ }^{36}$ For a detailed account of the changing idiom of barking, see Ian Trowell 'Spiel, Patter or Sound Effect: Tracking the Residual Voice on the Travelling Fun-Fair.' Journal of Interdisciplinary Voice Studies, Volume 3, Number 1, (April 2018) 7-20. See also Trowell's work on "The Fairground Noise," in La revue Politiques de communication, Hors-Série No.1 Sound Studies: À L'écoute du social (Presses universitaires de Grenoble, 2018). We should also acknowledge the highly attuned skills of the fairperson, who is far more responsive to changes in crowd expectation, cultural references and dynamics than most architects or urban planners.

37 DeLanda stresses that the density of interaction within a social network is linked to frequency of interaction along links between nodes, not physical density as this might be mistaken for in a crowd situation. Moreover, just because a node in a social network is well 
connected does not, or 'rarely... give[s] it ... the capacity to issue commands.' Assemblage Theory, 31.

38 "Given the general level of tightness (or looseness) established in a situation, and the orderly changes prescribed in this regard, it is worth noting that the normative stability found in the situation may be due to the presence of guardians who informally or formally have the special job of keeping "order." Thus, we read of the silentiarius, the Roman slave whose job it was to regulate the noise level maintained by other slaves. In our day, chaperones, referees, nursery-school teachers, judges, police, ward attendants, and ushers are among those who perform this function." Goffman, Behaviour in Public Places, 210. See also ibid, 18 , where Goffman notes there is usually someone responsible for getting a social occasion underway, as well as guiding activity and drawing it to a close.

39 Cross and Walton, The Playful Crowd, 8.

40 Roberts, Review of Fairground Safety, Section 4.32. The reports qualifies this assertion, noting how "[s]ome contributors, not all, were strongly of th[is] view".

41 Duncan Dallas The Travelling People (London: Macmillan, 1971), 84. More broadly, Dallas notes: "The gaff lads are the itinerant labourers who work on the rides and build up and pull down at the beginning and end of each gaff... [They] are casual labourers and can be hired for any length of time form a week-end to the whole of the season... [The gaff lad] is expected to work when there is work to be done. He has no hours, no overtime, no security, no prospects, and bad pay... Most gaff lads are between seventeen and twenty-one, although the age can go up to thirty." $84-5$.

42 "All persons in the gathering at large will be immersed in a common pool of unfocused interaction, each person, by his mere presence, manner, and appearance, transmitting some information about himself to everyone in the situation, and each person present receiving like information from all the others present, at least in so far as he is willing to make use of his receiving opportunities." Goffman, Behaviour in Public Places, 154. 
43 Ian Trowell, 'Spiel, patter or sound effect: Tracking the residual voice on the travelling fun fair', Journal of Interdisciplinary Voice Studies, 3:1, 2018, pp. 7-20, doi:

10.1386/jivs.3.1.7_1, p.10. Citing F. Brown, Fairground Strollers and Showfolk (Taunton: Ronda Books, 2001) 12.

44 Goffman, Behaviour in Public Places, 154. In Assemblage Theory, DeLanda explicitly develops Goffman's work on social encounters, but focusing on how conventions for conversation (and thus embarrassment) rather than the work I cite here. His interest is in how these can provide gatherings with "well-defined borders in space and time." 28.

45 Goffman, Behaviour in Public Places, 18. Elsewhere, Goffman emphasises that participants and bystanders all have roles to play in maintaining 'the integrity of the encounter'. ibid, 159.

46 'Given... an interaction frame of reference that is related to institutional analysis but analytically distinct from it, the main lines of interaction analysis can be laid out. We look within an act for the involvement it seems to express; we look to the involvement for the regulations by which it is bound; and we look to these regulations as a sign of what is owed to the gathering and its social occasion as realities in their own right.' Goffman, Behaviour in Public Places, 247.

47 For a very detailed analysis of the "Atmosphere Creator" Waltzer and its associations with Donk music, see Ian Trowell, "Atmosphere Creator: the Sounds of the Fairground," in Listening to Music: People, Practices and Experiences, Eds. Helen Barlow and David Rowland (Milton Keynes: Open University, 2017). Open access publication at http://ledbooks.org/proceedings2017/

48 Lieven De Cauter, 1993. 'The Panoramic Ecstasy: On World Exhibitions and the Disintegration of Experience.' Theory, Culture \& Society 10, no. 4: 1-23.

49 ibid., 193. Original emphasis.

50 ibid., 193. 
51 DeLanda, Assemblage Theory, 33. It would be interesting to trace a longer history of the fairmarket relationship, particularly the moves that began to stratify and separate them, as well as moments in their respective histories when the main activities they hosted changed (i.e from trade to pleasure fairs during the seventeenth and eighteenth centuries, and within the pleasure fairs, from attractions to rides). Accompanying these moments of change, official pressures (catalysts) can be identified, such as the Fairs Act 1871, but there are other legislative, soft-power and peer-pressure catalysts that also form part of this story.

${ }^{52}$ DeLanda sketches out the role of markets and bazaars as "actors in the explanations of the rise of Europe" in both $A$ Thousand Years (see Section 1: "Lavas and Magmas") and Assemblage Theory (see 14-5.) Beyond the localised activities, the balance of operations between local and regional markets involves physically distributed road networks, as well as a complex calendar (DeLanda refers to 'regularity' not calendar), and allows a complex socio-economic and cultural acts to be sustained between many different people with different interests and needs: the 'glue' for this example is synchronised price movements. Although the economy of the fair operates as much around desire and pleasure as it does with hard currency, the distributed network or assemblage of the fairground shares the same root and related operations. DeLanda's more developed work on markets \& bureaucracies, planned and unplanned cities, between self organized meshworks and hierarchies of uniform elements, and the complex interchange between the latter, would support a wider consideration of the travelling fair, one that is beyond the scope of this article. See $A$ Thousand Years, 65.

53 DeLanda, Assemblage Theory, $31 \mathrm{ff}$.

54 For example, the visitor's experience of the fair could register the temporal-historical passage of centuries legible in the urban fabric and spaces of the Market Square, although the temporal-experiential dimensions of this identity are perhaps more readily comprehensible. These too enjoy a variety of semi-autonomous phasings that would include the annual cycle of three-day take-over of the town by the fair, a weekday-weekend cycle, 
the diurnal cycle, an individual's visit to the fair, or a single ride or event. Similarly nested, the physical scales inflecting identity involve the individual body of the fair-goer, the individual ride, the town centre, the network of the 'Heart of England' and Back End Run fairs, the UK, Europe and beyond ('big ticket' rides such as Air travel globally). 